\title{
Lack of CaBP1/Caldendrin or CaBP2 Leads to Altered Ganglion Cell Responses
}

\author{
Raunak Sinha, ${ }^{1}$ Amy Lee, ${ }^{2}{ }^{-}$Fred Rieke, ${ }^{1}$ and ${ }^{1}$ Françoise Haeseleer ${ }^{3}$
}

DOI:http://dx.doi.org/10.1523/ENEURO.0099-16.2016

${ }^{1}$ Department of Physiology and Biophysics, Howard Hughes Medical Institute, University of Washington, Seattle, WA 98195, ${ }^{2}$ Departments of Molecular Physiology and Biophysics, Otolaryngology Head-Neck Surgery, and Neurology, University of lowa, lowa City, IA 52242, and ${ }^{3}$ Department of Physiology and Biophysics, University of Washington, Seattle, WA 98195

\section{Visual Abstract}
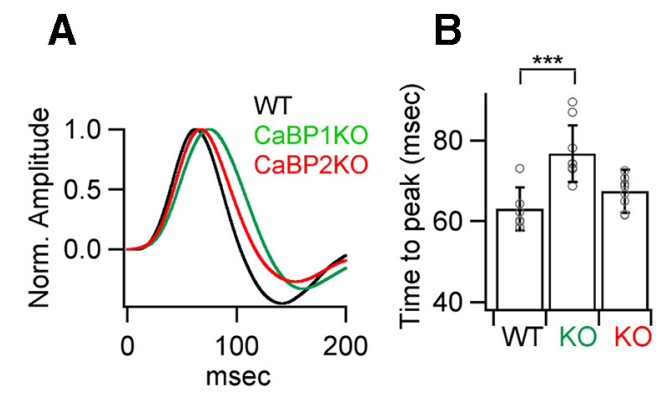

\section{ON alpha GC}

C

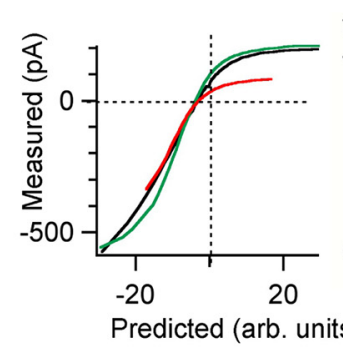

D

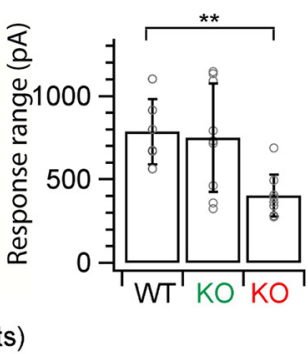

OFF transient GC
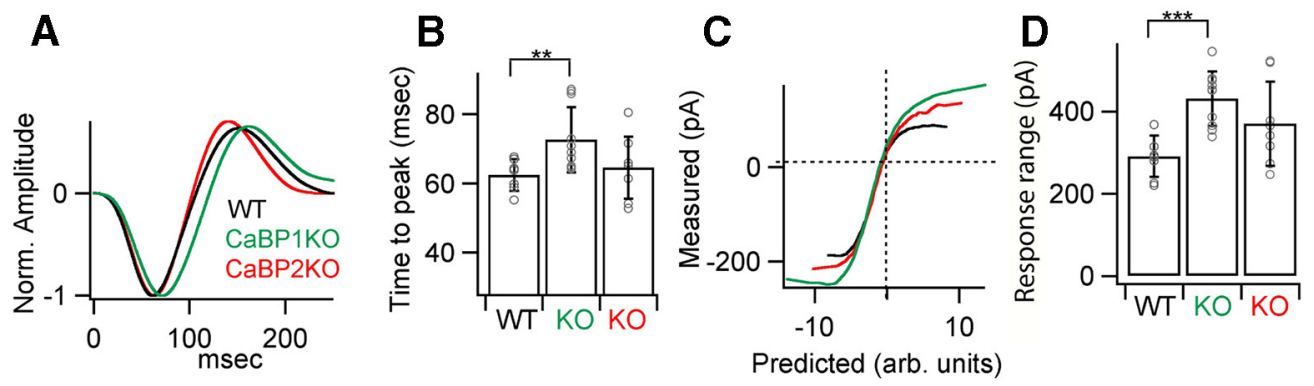

\section{Significance Statement}

Electrical signals generated by the photoreceptors in response to incident light are processed by diverse retinal neurons before being sent to the brain. $\mathrm{Ca}^{2+}$ signaling controls both cellular and synaptic mechanisms that shape signals as they are transmitted through the retina. $\mathrm{Ca}^{2+}$-binding proteins (CaBPs), including the calmodulin-like CaBPs, exert $\mathrm{Ca}^{2+}$-dependent effects on specific target proteins-e.g., ion channels. To determine whether CaBP1/caldendrin and CaBP2 are important for normal retinal function, we used $\mathrm{CaBP} 1 /$ caldendrin- and CaBP2-deficient mice. Although these proteins are not required for retinal development and maintenance, CaBP1/caldendrin and CaBP2 are important for normal transfer of light signals through the retina. 
Calcium-binding proteins (CaBPs) form a subfamily of calmodulin-like proteins that were cloned from the retina. CaBP4 and CaBP5 have been shown to be important for normal visual function. Although CaBP1/caldendrin and CaBP2 have been shown to modulate various targets in vitro, it is not known whether they contribute to the transmission of light responses through the retina. Therefore, we generated mice that lack CaBP2 or CaBP1/ caldendrin $\left(\mathrm{Cabp}^{-/-}\right.$and $\left.\mathrm{Cabp}^{-/-}\right)$to test whether these CaBPs are essential for normal retinal function. By immunohistochemistry, the overall morphology of $\mathrm{Cabp}^{-/-}$and $\mathrm{Cabp} 2^{-/-}$retinas and the number of synaptic ribbons appear normal; transmission electron microscopy shows normal tethered ribbon synapses and synaptic vesicles as in wild-type retinas. However, whole-cell patch clamp recordings showed that light responses of retinal ganglion cells of $\mathrm{Cabp} 2^{-/}$and $\mathrm{Cabp} 1^{-/-}$mice differ in amplitude and kinetics from those of wild-type mice. We conclude that $\mathrm{CaBP} 1 /$ caldendrin and CaBP2 are not required for normal gross retinal and synapse morphology but are necessary for the proper transmission of light responses through the retina; like other CaBPs, CaBP1/caldendrin and CaBP2 likely act by modulating presynaptic $\mathrm{Ca}^{2+}$-dependent signaling mechanisms.

Key words: bipolar cells; calcium-binding proteins; ganglion cells; knockout mice; light response; retina

\section{Introduction}

CaBPs are neuronal $\mathrm{Ca}^{2+}$-binding proteins with high homology to calmodulin (CaM; Haeseleer et al., 2000). CaBPs possess four EF-hand $\mathrm{Ca}^{2+}$-binding domains, but unlike CaM, only three of them are capable of binding $\mathrm{Ca}^{2+}$. CaM and CaBPs can interact with similar targets, but their differences can underlie distinct forms of regulation. For example, $\mathrm{CaM}$ and $\mathrm{CaBPs}$ can both bind to voltage-gated $\mathrm{Ca}_{v} 1 \mathrm{~L}$-type $\mathrm{Ca}^{2+}$ channels, but CaM promotes $\mathrm{Ca}^{2+}$-dependent inactivation, whereas CaBPs oppose this process and prolong channel opening (Zhou et al., 2004; Cui et al., 2007).

CaBPs are expressed in the retina and the cochlea; CaBP1/caldendrin is also expressed in other neuronal tissues, including the brain (Seidenbecher et al., 1998; Menger et al., 1999; Haeseleer et al., 2000, 2004; Yang

Received April 27, 2016; accepted October 8, 2016; First published October 20, 2016.

The authors report no conflict of interest.

Author Contributions: R.S., F.R., and F.H. designed and performed research and analyzed the data. A.L. contributed unpublished reagents. All authors contributed to writing and approval of the final manuscript.

The research was supported by a University of Washington Royalty Research Fund, University of Washington bridge funding, and National Institutes of Health (NIH) grant R01 EY020850 to F.H.; the Howard Hughes Medical Institute and NIH grant EY11850 to F.R.; NIH grants NS084190 and DC009433 and a Carver Research Program of Excellence to A.L.; and a long-term fellowship by Human Frontier Science Program to R.S.

Acknowledgments: We thank Edward Parker at the University of Washington for his great expertise and help with transmission electron microscopy. We thank Jacqueline Mudd at the Embryonic Stem Cell Core-Siteman Cancer Center and Renate Lewis at the Hope Center Transgenic Vectors Core (Washington University, St. Louis) and Robert Hunter at the University of Washington Transgenic Resource Program for their expert work in generating the CaBP2 KO mice. We thank Rachel Wong (University of Washington, Seattle, WA) for the gustducin-GFP mouse retinas, the Zebrafish International Resource Center supported by \#RR12546 (National Center for Research Resources, National Institutes of Health) for the anti-synaptotagmin 2 antibody, Dr. Arlene Hirano (University of California-Los Angeles, Los Angeles) for the anti-NK3R antibody, and Dr. Roger Tsien (Howard Hughes Medical Institute, University of California-San Diego, San Diego) for tdTomato.

Correspondence should be addressed to Françoise Haeseleer, University of Washington, Department of Hematology, 1705 NE Pacific St., Box 357710, Seattle, WA 98195. E-mail: fanfan@u.washington.edu.

DOI:http://dx.doi.org/10.1523/ENEURO.0099-16.2016

Copyright ( 2016 Sinha et al.

This is an open-access article distributed under the terms of the Creative Commons Attribution 4.0 International, which permits unrestricted use, distribution and reproduction in any medium provided that the original work is properly attributed. et al., 2006; Cui et al., 2007; Kim et al., 2014). CaBP4 has been well characterized and is essential for normal neurotransmitter release from photoreceptors through enhanced activation of $\mathrm{Ca}_{\mathrm{v}} 1.4$ L-type channels (Haeseleer et al., 2004; Shaltiel et al., 2012). Mutations in the genes encoding CaBP4 and $\mathrm{Ca}_{\mathrm{v}} 1.4$ lead to similar visual disorders in humans and animal models (Bech-Hansen et al., 1998; Strom et al., 1998; Boycott et al., 2001; Wutz et al., 2002; Haeseleer et al., 2004; Mansergh et al., 2005; Zeitz et al., 2006; Aldahmesh et al., 2010; Khan et al., 2012; Bijveld et al., 2013; Khan, 2013). CaBP5 is expressed in rod bipolar cells and type 3 OFF and type 5 ON cone bipolar cells (Haeseleer et al., 2000; Haverkamp et al., 2003b) and is important for normal sensitivity of retinal ganglion cell light responses, likely through regulation of neurotransmitter release (Cui et al., 2007; Rieke et al., 2008; Sokal and Haeseleer, 2011).

CaBP1 and CaBP2 transcripts are alternatively spliced, resulting in short (S-) and long (L-) forms of these proteins (Haeseleer et al., 2000; Sokal et al., 2000; Haeseleer and Palczewski, 2002). A third splice variant of CaBP1, named caldendrin (CD), incorporates a different $\mathrm{N}$-terminal exon and lacks the $\mathrm{N}$-terminal myristoylation site present in Sand L-CaBP1 (Seidenbecher et al., 1998). For simplicity, we will use CaBP1/CD to refer to all three variants (SCaBP1, L-CaBP1, and caldendrin) and CaBP1 to refer to S-CaBP1 and L-CaBP1. CaBP1/CD is expressed in different regions of the brain and is localized pre- and postsynaptically (Seidenbecher et al., 1998; Kim et al., 2014). In the retina, CaBP1/CD is expressed in OFF cone bipolar cells and amacrine cells (Menger et al., 1999; Haeseleer et al., 2000; Haverkamp and Wässle, 2000). CaBP1 modulates voltage-gated calcium channels (Hardie and Lee, 2016), with different effects on channel activity depending on the channel subtype (Lee et al., 2002; Zhou et al., 2004; Yang et al., 2006; Cui et al., 2007; Findeisen and Minor, 2010; Few et al., 2011). CaBP1 also regulates inositol 1,4,5-triphosphate receptors (Yang et al., 2002; Haynes et al., 2004; Li et al., 2013) and various enzymes in vitro (Haeseleer et al., 2000; Sokal et al., 2000). Caldendrin interacts with light chain 3 of microtubule-associated protein 1A, A-kinase anchoring proteins 79/150, and the Jacob protein that couples $\mathrm{N}$-methyl-d-aspartate receptor signaling to the nucleus (Seidenbecher et al., 2004; Dieterich et al., 2008; Gorny et al., 2012). CaBP2 regulates 
voltage-gated calcium channels, inositol 1,4,5-triphosphate receptors, and various enzymes (Haeseleer et al., 2000; Sokal et al., 2000; Yang et al., 2006; Cui et al., 2007). A mutation in the Cabp2 gene is associated with hearing impairment in humans, likely through dysregulation of the $\mathrm{Ca}_{\mathrm{v}} 1.3$ channels present in auditory inner hair cells, which are modulated by CaBP2 (Schrauwen et al., 2012).

Despite the identification of a large variety of interacting partners, the contributions of $\mathrm{CaBP} 1 / \mathrm{CD}$ and $\mathrm{CaBP} 2$ to the transmission of light responses through the retina is unknown. In this study, we used CaBP1/CD knockout $\left(\mathrm{KO} ; \mathrm{Cabp}^{-/-}\right)$and newly generated $\mathrm{CaBP} 2 \mathrm{KO}\left(\mathrm{Cabp}^{{ }^{-/-}}\right)$ mice to investigate the importance of CaBP1/CD and CaBP2 for normal visual function. We find that both CaBP1/CD and CaBP2 regulate ganglion cell light responses and have different effects on their contrast sensitivity.

\section{Material and Methods}

\section{Antibodies}

Commercially available antibodies were as follows: Alexa Fluor 555 goat anti-rabbit (Invitrogen, San Diego, CA; cat. \# A21429 RRID:AB_141761), Alexa Fluor 488 goat anti-rabbit (Thermo Fisher Scientific, Waltham, MA; cat. \# A11034 RRID:AB_10562715), Alexa Fluor 555 goat antirat (Invitrogen; cat. \# A21434 RRID:AB_141733), Alexa Fluor 568 goat anti-mouse IgG2a ( $\gamma 2 \mathrm{a}$; Innovative Research of America, Toledo, OH; cat. \# A21134 RRID: AB_1500825), Alexa Fluor 488 goat anti-mouse lgG1 ( $\gamma 1$; Invitrogen; cat. \# A21121 RRID:AB_141514), anticalretinin (Millipore, Bedford, MA; cat. \# MAB1568 RRID: AB_94259), anti-synaptotagmin 2 (Zebrafish International Resource Center, Eugene, OR; cat. \# znp-1 RRID: AB_10013783), anti-Ctbp2/ribeye (BD Biosciences, Franklin Lakes, NJ; cat. \# 612044 RRID:AB_399431), anti-NK3R (rabbit polyclonal, gift of Dr. Arlene Hirano, University of California-Los Angeles, Los Angeles), anti-green fluorescent protein (GFP; Abcam, Cambridge, UK; cat. \# ab13970 RRID: AB_300798), anti-calsenilin (Millipore; cat. \# 05-756 RRID: AB_309969), and anti-CaBP1, anti-CaBP2, and anti-CaBP5 (Haeseleer et al., 2000).

\section{Generation of rat anti-CaBP1/CD and rat anti-CaBP2 antibodies}

Anti-CaBP1/CD and anti-CaBP2 polyclonal antibodies were raised in rats by subcutaneous immunization with purified S-CaBP1 or S-CaBP2 recombinant proteins mixed with Freund's adjuvant (Cocalico Biologicals, Reamstown, PA). For affinity purification of rat antiCaBP1/CD or anti-CaBP2 antibodies, purified CaBP1 or CaBP2 was coupled to cyanogen bromide-activated Sepharose (GE Healthcare, Piscataway, NJ) according to the manufacturer's protocol. After loading of a 10-fold dilution of the sera in PBS, the columns were washed with 20 volumes of PBS. The bound antibodies were eluted with $0.1 \mathrm{M}$ glycine buffer, $\mathrm{pH} 2.5$, and dialyzed overnight against PBS.

\section{Generation and genotyping of $\mathrm{Cabp2}^{-1-}$ mice}

All animal procedures were performed in accordance with the University of Washington Animal Care and Use Committee's regulations. A $\sim 2.1-\mathrm{kb}$ fragment covering part of exon 2 to part of intron 5 of Cabp2 gene was amplified first from C57BI/6 genomic DNA by PCR with primer FH939 (5'-GTCGACTAAGTAGCTGAGACCAG AAGAGATCGAAG-3') that was extended with a Sall restriction site and includes a stop codon in all three open reading frames and primer FH940 (5'-GGTACCAGGAGG GCTCAGTTGCTCACATTA-3') that was extended with a $\mathrm{Kpnl}$ site. After sequencing of this 2.1-kb fragment, it was cloned into the targeting vector Sall and Kpnl opened between the neomycin phosphotransferase gene and herpes simplex virus thymidine kinase gene. The long arm of $\sim 5.2$ $\mathrm{kb}$ covering the promoter region of the Cabp2 gene upstream the ATG was amplified in two fragments. The upstream fragment of $2 \mathrm{~kb}$ was amplified by PCR with primer FH937 (5'-GCGGCCGCTCGTGGTTTCAGGTGCTCTACACA $-3^{\prime}$ ) that was extended with a Notl site and primer FH947 (5'-TAAGGTCTTAGAGGGTCTGACAGG-3') that covers a Spel restriction site. A 3.2-kb fragment upstream of the CaBP2 initiation codon was amplified by PCR with primer FH938 (5'-ACCCAGGTTTCTGGCCTTATGTCT-3') that also covers the Spel restriction site and FH948 (5'TACCGACTGACTCATGCCTAGGTT-3') that hybridizes a few bases downstream of the CaBP2 initiation codon. All fragments were cloned in the PCRII-TOPO vector and sequenced. A tdTomato vector (originally a gift from Dr. Roger Tsien, provided by Dr. Rachel Wong) was modified by mutagenesis using QuikChange Lightning Multi Site-Directed Mutagenesis (Agilent Technologies, Santa Clara, CA) to introduce a Nhel site after the SV40 polyadenylation site with primer FH1043 (5'-GTATCTTAAGGCGTAGCTAGCAAGCTTTAATATTITGTTAAAATTCGC-3') and delete the internal Ncol site in tdTomato with primer $\mathrm{FH} 1044$ (5'CGTAATGCAGAAGAAGACGATGGGCTGGGAGGCCTCC$\left.3^{\prime}\right)$. tdTomato was then fused to the CaBP2 promoter as a fragment Ncol-Nhel and transferred together in the targeting vector as Notl-Bglll and Bglll-Nhel fragments.

The Kpnl linearized targeting vector was electroporated into B6/BLU embryonic stem cells. Recombinant clones were selected on medium containing G418. Transfected embryonic stem (ES) cell clones were first screened through PCR analysis. To screen for homologous recombination, we used primers FH 1064 (5'-GGGTCGTTTGTTC GGATCCTCTAGAGTC-3') located in the neo cassette and FH1139 (5'-TACACAGGCTCACCGAGACATCAT-3') hybridizing approximately 163 bp downstream of the $3^{\prime}$ end of the short arm in the Cabp2 gene and amplifying a fragment of $\sim 2.3 \mathrm{~kb}$. A control PCR for the wild-type (WT) gene was made with primers $\mathrm{FH} 1139$ and $\mathrm{FH} 1140$ (5'ACCAGGCATGGAGTTGGGTATGAA-3') hybridizing in intron $2 A, 480$ bp upstream of the $5^{\prime}$ end of the short arm of the Cabp2 gene and amplifying a fragment of $\sim 2.75 \mathrm{~kb}$. Targeted disruption of the Cabp2 gene was then confirmed by Southern blot analysis. Ten micrograms of genomic DNA was digested with Mfel and hybridized with a $0.6-\mathrm{kb} 5^{\prime}$-end probe located $100 \mathrm{bp}$ upstream of the $5^{\prime}$ end of the long arm (Fig. 1). This probe hybridized to a 
A

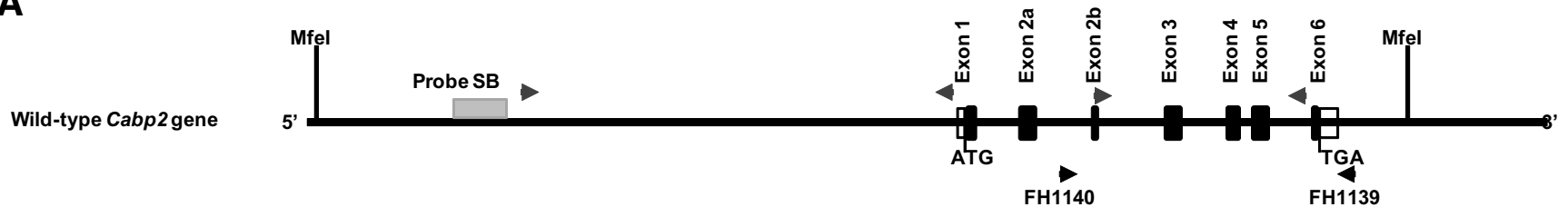

Targeting vector
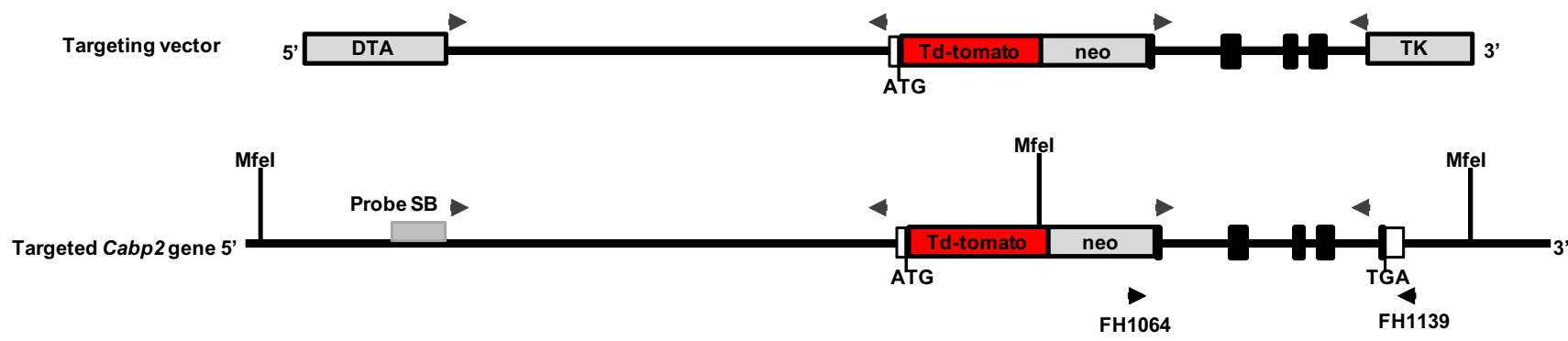

$1 \mathrm{~kb}$

B

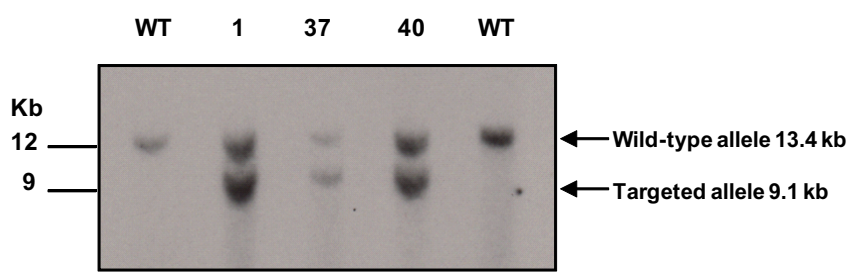

C

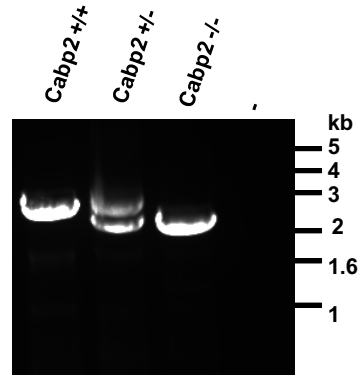

Figure 1. Targeting of the Cabp2 gene. A, Scheme of the mouse Cabp2 gene with its exons. Arrows above the scheme indicate primers used to clone by PCR Cabp2 genomic fragments. The PGK-DTA and HSV-TK cassettes were included in the targeting vector for negative selection in transfected ES cells. In the targeting vector, the neo cassette (positive selection) replaces exon 1 and exon $2 \mathrm{~A}$ of the Cabp2 gene. The targeting vector is constructed by using a $\sim 5-\mathrm{kb}$ DNA fragment as long arm that extends upstream of the initial ATG and covers the CaBP2 promoter. tdTomato was cloned and fused on the initiation codon of CaBP2. The short arm is a 2.0-kb genomic fragment encompassing exon 2B to intron 5 of the Cabp2 gene. Arrows (FH1064, FH1139, and Fh1140) below the scheme indicate primers used to select targeted Cabp2 allele. The location of Mfel restriction site as well as the probe (probe SB) used for analysis of the targeted allele using Southern blot are also indicated. B, Southern blot analysis of ES cell clones. Mfel-digested genomic DNA isolated from wild-type B6/Blu ES cells (WT) or targeted clones 1, 37, and 40 was analyzed by Southern blot with an external probe as shown in $\boldsymbol{A}$ and shows a fragment of $13.4 \mathrm{~kb}$ for the wild-type Cabp2 allele and a fragment of $9.1 \mathrm{~kb}$ for the targeted Cabp2 allele. C, PCR-based analysis of mice for Cabp2 targeting. A 2.3- and 2.75-kb PCR product is amplified with primers FH1140 and FH1139 as shown in $\boldsymbol{A}$ for the WT Cabp2 allele and with primers FH1064 and FH1139 for the targeted allele, respectively.

Mfel fragment of $\sim 13.4 \mathrm{~kb}$ of the WT allele or a Mfel fragment of $\sim 9.1 \mathrm{~kb}$ if the Cabp2 gene is targeted.

One targeted ES clone was injected into C57BL/6J blastocysts. One $80 \%$ male chimera was crossed with C57BL/6J mice, and agouti offspring were genotyped by PCR to verify germline transmission. Confirmation of Cabp2 gene targeting was first performed with primers $\mathrm{FH} 1139, \mathrm{FH} 1140$, and $\mathrm{FH} 1064$ as indicated above. For routine genotyping of the offspring, the WT allele was identified with primers FH1214 (5'-CCCTAAGACACCCAG ACAGATGA-3', located in intron 2A) and FH1218 (5'GAAGTGTCAGCCAGATGGACAAA-3', hybridizing in intron $2 \mathrm{~B}$ ) that generate a PCR product of $0.4 \mathrm{~kb}$. The targeted Cabp2 allele was identified with primers $\mathrm{FH} 1218$ and FH1384 (5'-TGGAGAGGCTATTCGGCTATGA-3', , lo- cated in the neo cassette) that produces a PCR product of $\sim 1.07 \mathrm{~kb}$.

\section{RT-PCR analysis of CaBP1 and CaBP2 transcripts}

Total RNAs were isolated from mouse retina using RNeasy kit (Qiagen, Valencia, CA). Total RNA (1 $\mu \mathrm{g})$ was subjected to first-strand cDNA synthesis using Superscript III reverse transcriptase and oligo(dT) in a volume of $20 \mu \mathrm{l}$ according to the manufacturer's protocol (Invitrogen). Short and long CaBP1 were amplified with common forward FH705 (5'-CACCATGGGCAACTGCGTCAAGT CG-3') and reverse FH706 (5'-TCAGCGAGACATCAT CCGGACAAAC-3') primers. Caldendrin was amplified with primers FH1089 (5'-ACACCAATCATATCTGCC GTCTCC-3') and FH1093 (5'-GCGATGGGGAGGAACGG 
GGGCT-3'). Short and long CaBP2 were amplified with common forward K122 (5'-TCCGGGCCTGGCATGGTTC$\left.3^{\prime}\right)$ and reverse FH1410 (5'-CCGAACAAATTCTTCAAAGT CAACC-3'). Amplification of glyceraldehyde 3-phosphate dehydrogenase (GAPDH) forward (5'-GAAGGGCTAA TGACCACAGTCCAT-3') and GAPDH reverse (5'-TAG CCATATTCGTTGTCGTACCAGG-3') was used as a positive control. The PCR conditions were as follows: $94^{\circ} \mathrm{C}$ for $2 \mathrm{~min}$, 35 cycles of $94^{\circ} \mathrm{C}$ for $15 \mathrm{~s}, 64^{\circ} \mathrm{C}$ for $30 \mathrm{~s}$, and $72^{\circ} \mathrm{C}$ for $1 \mathrm{~min}$, then $72^{\circ} \mathrm{C}$ for $7 \mathrm{~min}$.

\section{Immunohistochemistry}

Eyecups from 6-week-old to 3-month-old Cabp $1^{-1-}$, $\mathrm{Cabp}^{-/-}, \mathrm{Cabp}^{-/-} / \mathrm{Cabp2}^{-/-}$, or WT mice of either sex were fixed in $4 \%$ paraformaldehyde in $0.1 \mathrm{M}$ phosphate buffer, pH 7.4 (PB), for $1 \mathrm{~h}$. After fixation, tissues were immersed in a graded sucrose series to $20 \%$ sucrose in $0.1 \mathrm{M}$ PB and embedded in $33 \%$ optimum cutting temperature compound (Miles, Elkhart, IN) diluted with $20 \%$ sucrose in PB before being frozen. Eye tissues were cut in $12-\mu \mathrm{m}$ sections. To block nonspecific labeling, retinal sections were incubated with 3\% normal goat serum in PBST buffer (10 mM sodium phosphate, $150 \mathrm{~mm} \mathrm{NaCl}$, $0.1 \%$ Triton $\mathrm{X}-100, \mathrm{pH} 7.4)$ for 20 min at room temperature. Sections were then incubated overnight at $4^{\circ} \mathrm{C}$ with purified rat anti-CaBP1/CD 1:50 dilution or rat anti-CaBP2 1:20 dilution. Alexa Fluor 555-conjugated goat anti-rat IgG and Hoechst stain (1:2000) were reacted with the sections for $1 \mathrm{~h}$ at room temperature. The sections were rinsed in PBST and mounted with Prolong antifade reagent (Invitrogen). As indicated, some sections were incubated overnight at $4^{\circ} \mathrm{C}$ with a mix of rat or rabbit anti-CaBP1/CD or antiCaBP2 antibodies and rabbit anti-NK3R at 1:500 dilution, mouse anti-Syt2 at 1:200, mouse anti-calretinin at 1:1000, chicken anti-GFP at 1:1000, mouse anti-calsenilin at 1:1000, or rabbit anti-CaBP5 at 1:200. A mix of Alexa Fluor 555conjugated goat anti-rat lgG (1:400) and Alexa 488-conjugated goat anti-rabbit IgG (1:400), Alexa Fluor 488conjugated goat anti-mouse IgG (1:400), or Alexa Fluor 488conjugated goat anti-chicken IgG (1:400) was then reacted with the sections for $1 \mathrm{~h}$ at room temperature.

For the analysis of whole-mount retinas, the mouse retinas were fixed for $1 \mathrm{~h}$ in $4 \%$ paraformaldehyde in PB before dissection, incubated with $5 \%$ normal goat serum in PBST buffer overnight at $4^{\circ} \mathrm{C}$, and incubated overnight at $4^{\circ} \mathrm{C}$ with a mix of anti-Syt2 $(1: 200)$ or anti-NK3R $(1: 500)$ and anti-Ctbp2 (1:1000). After three washes for $15 \mathrm{~min}$ in PBST, a mix of Alexa Fluor 568 goat anti-mouse IgG2a $(\gamma 2 a)$ and Alexa Fluor 488 goat anti-mouse IgG1 $(\gamma 1)$ or a mix of Alexa Fluor 488 goat anti-mouse IgG and Alexa Fluor 555 goat anti-rabbit was reacted with the sections overnight at $4^{\circ} \mathrm{C}$. After three washes in PBST, the retinal whole mounts were mounted with the photoreceptor side down in Prolong antifade reagent and analyzed under a confocal microscope (LSM710, Zeiss, Oberkochen, Germany). Immunofluorescent images were obtained with $63 \times / 1.4,40 \times / 1.1$, or $40 \times / 1.3$ NA objectives (Zeiss).

For quantification of the Ctbp2-labeled synaptic ribbons, confocal images of en face views in whole mounts of WT, $\mathrm{Cabp}^{-/-}$, and $\mathrm{Cabp2}^{-/-}$retinas were acquired using a $63 \times /$
1.4 objective at a voxel size of $0.028 \times 0.028 \times 0.359 \mu \mathrm{m}$ $(x-y-z)$. The sublamina containing the axon terminals of cone OFF bipolar type 1 and type 2 was identified by colabeling with anti-NK3R and anti-Ctbp2. The axon terminals of cone ON bipolar type 6 were visualized by colabeling with antisyt2 and Ctbp2. Ctbp2-labeled synaptic ribbons were counted in images of six randomly chosen $25-\mu \mathrm{m}^{2}$ areas across the retina of four mice for each phenotype. The statistical analysis was done using the two-tailed Student's $t$-test. Data are expressed as mean \pm SE.

\section{Electron microscopy}

Eye cups from WT, Cabp $1^{-/}$, and Cabp2 ${ }^{-/-}$mice of either sex were fixed in $4 \%$ glutaraldehyde in $0.1 \mathrm{M}$ sodium cacodylate buffer at $4^{\circ} \mathrm{C}$. After four washes in $0.13 \mathrm{M}$ PB, eyecups were dissected and postfixed in $1 \%$ buffered osmium tetroxide for $2 \mathrm{~h}$ on ice. After another four washes in $\mathrm{PB}$, the retinas were en bloc stained in $1 \%$ uranyl acetate overnight at $4^{\circ} \mathrm{C}$, dehydrated through a graded series of ethanol and two incubations in propylene oxide, and infiltrated in a 1:1 mixture of propylene oxide:epon araldite and two incubations in epon araldite, before polymerization at $60^{\circ} \mathrm{C}$. Seventy-nanometer sections were cut on a Leica UC7 ultra microtome and stained with Reynolds lead citrate. The sections were viewed and images recorded on a JEOL 1230 electron microscope (JEOL, Peabody, MA). Images of bipolar cell terminals were analyzed in the outer part of the inner plexiform layer within 2-5 $\mu \mathrm{m}$ from the inner nuclear layer where type 1 and type 2 cone OFF bipolar cell axon terminals are located. Images of photoreceptor synapses with bipolar cells were taken in the outer plexiform layer.

\section{Electrophysiology and visual stimulation}

Experiments were conducted on whole-mount retinal preparations taken from dark-adapted WT, Cabp $1^{-/-}$, or $\mathrm{Cabp2}^{-/-}$mice (Schwartz et al., 2012). Isolated retina was stored in oxygenated $\left(95 \% \mathrm{O}_{2} / 5 \% \mathrm{CO}_{2}\right)$ Ames medium (Sigma-Aldrich, St. Louis, MO) at $\sim 32-34^{\circ} \mathrm{C}$. Isolated retinas were flattened onto poly-L-lysine slides (whole mount; Schwartz et al., 2012), placed in a custom microscope, and perfused with Ames solution at a rate of $\sim 8$ $\mathrm{mL} / \mathrm{min}$. Retinal neurons were visualized and targeted for patch-clamp recordings using infrared light (>950 nm). Voltage-clamp recordings were obtained using pipettes (2-3 M $\Omega$ ) filled with an intracellular solution containing (in $\mathrm{mm}$ ): $105 \mathrm{Cs}$ methanesulfonate, 10 tetraethylammonium chloride, 20 HEPES, 10 EGTA, 2 QX-314, 5 Mg-ATP, 0.5 Tris-GTP ( $\sim 280 \mathrm{mOsm}, \mathrm{pH} \sim 7.3$ with $\mathrm{CsOH})$. Alexa 594 dye (100-200 microM) was included in the intracellular solution to image the ganglion cells post recording as shown in Figs. 8 and 9. Full-field light stimuli (diameter $500 \mu \mathrm{m})$ were delivered to the tissue from an LED with peak spectral output at $405 \mathrm{~nm}$. Recordings were performed from ventral retina. All ganglion cell recordings shown were recorded at a background light level of $\sim 900$ $\mathrm{R} * / \mathrm{S}$ cone/s, where cones dominate retinal responses. The statistical analysis was done using the two-tailed unpaired Student's $t$-test; $* p<0.05, * * p<0.01$, ***p $<$ 0.001 ; error bars indicate SD. 


\section{Results}

\section{Generation of $\mathrm{Cabp2}^{-/-}$mice}

Two splice variants of CaBP2, S-CaBP2, and L-CaBP2 exist and differ by the absence or presence of exon $2 \mathrm{~A}$ (Fig. 1A; Seidenbecher et al., 1998; Haeseleer et al., 2000; Sokal et al., 2000). To generate Cabp2 ${ }^{-/-}$mice, we designed a targeting vector to replace exon 1 and exon 2a of the Cabp2 gene with tdTomato and a PGK-neo cassette as shown in Figure $1 A$. Stop codons were also introduced in all three open reading frames of exon $2 B$ to prevent expression of any CaBP2 variants. PCR screening of ES cells identified three targeted ES cell clones for which targeting of the Cabp2 allele was further verified using Southern blot (Fig. 1B). Injection of targeted ES clone 37 produced one male chimera that gave germline transmission. Targeting of the Cabp2 gene was confirmed in the offspring by PCR on genomic DNA (Fig. 1C). Cabp2 $2^{-/}$ mice were viable and did not show any apparent physiological deficits or breeding problems.

\section{Analysis of CaBP1/CD and CaBP2 expression in KO mice}

The generation of Cabp $1^{-/-}$mice was described by Kim et al. (2014). As a first step in the characterization of Cabp $1^{-1-}$ mice, we verified the absence of CaBP1/CD expression in the retina. Because exon 1 of caldendrin and exon 1 of S- and L-CaBP1 were removed in Cabp $1^{-/-}$ mice, all three splice variants were targeted. The absence of transcripts for all three splice variants was confirmed by reverse-transcription (RT)-PCR using retinal RNA of $\mathrm{Cabp}^{-1-}$ mice (Fig. $2 A$ ), whereas all three variants were observed in Cabp $1^{+/+}$mice. As a positive control, PCR was performed with primers designed to detect GAPDH and showed transcripts in both Cabp $1^{+/+}$and Cabp $1^{-/-}$ mice. The absence of CaBP1/CD proteins in the retina of Cabp $1^{-1-}$ mice (Fig. 2B) was confirmed using immunohistochemistry. Staining was not detected in $\mathrm{Cabp} 1^{-/-}$mice with anti-CaBP1/CD antibodies recognizing all three splice variants.

We also verified the absence of CaBP2 expression in the newly generated $\mathrm{Cabp2}^{-/-}$mice. Using RT-PCR, transcripts were not detected for CaBP2 in $\mathrm{Cabp2}^{-/-}$retina (Fig. 2C) that showed transcripts for the GAPDH positive control. Using immunohistochemistry, we tested that CaBP2 proteins are not present in Cabp2 ${ }^{-/-}$mice. Unfortunately, because of the high homology between CaBP1/CD and CaBP2 proteins, our anti-CaBP2 antibodies recognize both CaBP1/CD and CaBP2. As a consequence, signals were still observed in the inner nuclear layer of $\mathrm{Cabp2}^{-/-}$mouse retina immunolabeled with antiCaBP2 (Fig. 2D). This residual signal was confirmed to be due to cross-reactivity of anti-CaBP2 antibodies with CaBP1/CD proteins as demonstrated by the absence of signals in $\mathrm{Cabp1}^{-1-} / \mathrm{Cabp2}^{-/}$double $\mathrm{KO}$ retinas immunolabeled with anti-CaBP2 (Fig. 2D). Therefore, specific labeling of CaBP2 proteins can be visualized with our antiCaBP2 antibodies in Cabp $1^{-/-}$mouse retina. Altogether, these results confirmed that $\mathrm{CaBP} 1 / \mathrm{CD}$ and $\mathrm{CaBP} 2$ are not expressed in $\mathrm{Cabp}^{-/-}$and $\mathrm{Cabp2}^{-/-}$mice.

\section{Analysis of retinal morphology in Cabp1 $1^{-/-}$mice}

CaBP1/CD is expressed in the inner retina, specifically in amacrine cells and in OFF cone bipolar cells (Fig. 3; Table 1; Menger et al., 1999; Haeseleer et al., 2000; Haverkamp and Wässle, 2000; Haverkamp et al., 2003a). Some CaBP1/CD staining can also be observed in cells in the ganglion cell layer that may be displaced amacrine cells (Menger et al., 1999). As shown in Figure 3A, all cells labeled with anti-neurokinin receptor 3 (NK3R), which labels type 1 and type 2 OFF cone bipolar cells, were also labeled with anti-CaBP1/CD (Haverkamp et al., 2003a; Pignatelli and Strettoi, 2004). Synaptotagmin 2 (Syt2), another label for type 2 OFF cone bipolar cells (Wässle et al., 2009), colocalized with CaBP1/CD in the outer inner plexiform layer (IPL) (Fig. 3C). Some amacrine cells labeled with anti-calretinin antibodies were also immunostained with anti-CaBP1/CD (Fig. 3B).

To determine whether the absence of CaBP1/CD triggers structural changes of the retina, we analyzed the morphology of the retinal cells lacking CaBP1/CD using antibodies against these marker proteins. NK3R and Syt2 immunolabeling showed normal bipolar cell morphology and normal thickness of the INL and IPL in Cabp $1^{-/-}$ compared with Cabp $1^{+/+}$retina (Fig. $3 D, F$ ). Calretinin immunostaining demonstrated normal stratification of the IPL of Cabp $1^{-1-}$ retina (Fig. 3E). To investigate whether lack of CaBP1/CD results in synaptic alterations, we analyzed retinas colabeled with anti-Syt2 or anti-NK3R and anti-ribeye/CtBP2 that labels synaptic ribbons in both the IPL and the outer plexiform layer (OPL). We analyzed the synapses in both plexiform layers because CaBP1/CD is expressed throughout the cone bipolar cells. Normal horseshoe-shaped and punctuate staining of the synaptic ribbons was observed in the IPL (Fig. 4A) and OPL (Fig. $4 C$ ) of $\mathrm{Cabp}^{+/+}$and $\mathrm{Cabp}^{-/-}$mouse retina. We quantified the synaptic ribbons labeled with anti-Ctbp2 in 25$\mu \mathrm{m}^{2}$ fields of OPL and IPL of WT and Cabp $1^{-/-}$mice. The density of synaptic ribbons in WT and $\mathrm{Cabp}^{1^{-/-}}$mice did not differ significantly (Table 2).

Synaptic terminals were analyzed at higher magnification using transmission electron microscopy to look for more subtle changes. Cone synapse morphology was normal, showing invagination of a pair of horizontal cells and a cone ON bipolar cell (Fig. 4D). Normal membraneanchored synaptic ribbons and tethered vesicles were observed in both IPL and OPL of $\mathrm{Cabp}^{+/+}$and $\mathrm{Cabp} 1^{-/-}$ retina (Fig. 4B, D). These results suggest that CaBP1/CD is not required for normal development or maintenance of overall retinal morphology.

\section{CaBP2 localization in bipolar cells of the retina}

To determine the consequences of CaBP2 deficiency, we first determined the distribution of CaBP2 in the mouse inner retina. Because our anti-CaBP2 antibody reacts with both $\mathrm{CaBP} 1 / \mathrm{CD}$ and CaBP2 (Fig. 2D), and because there are no retina morphological changes in $\mathrm{Cabp1}^{-/-}$, we chose to study CaBP2 localization using $\mathrm{Cabp1}^{-/-}$mouse retina. Anti-CaBP2-labeled axons ramified in two distinct layers of the IPL, likely corresponding to ON and OFF cone bipolar cells (Fig. 2D). To determine 
A

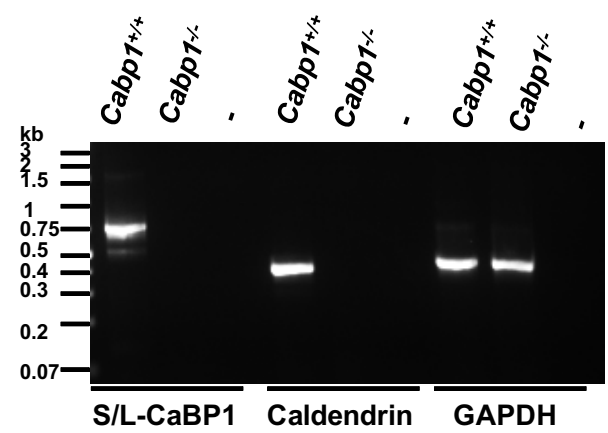

B
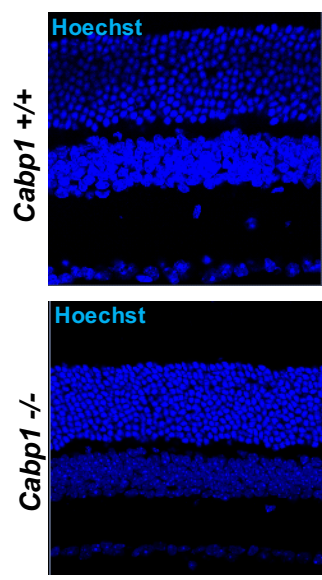

C

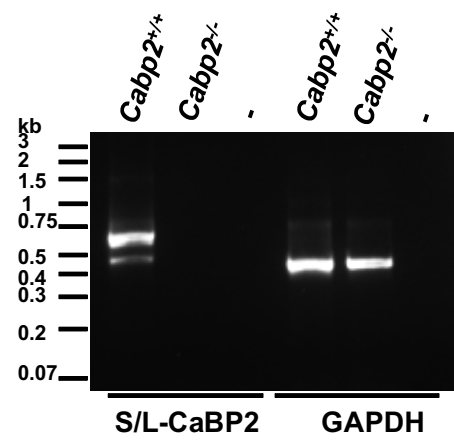

D
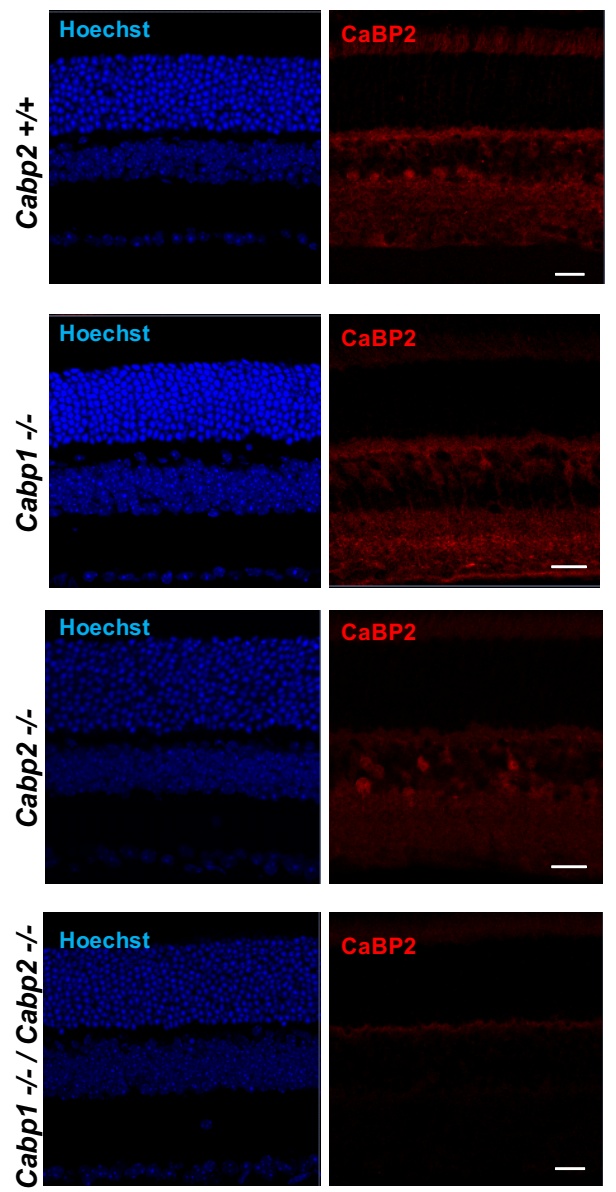

Figure 2. Analysis of the expression of CaBP1/CD or CaBP2 in WT, Cabp1 $1^{-/}$, or Cabp2 $2^{-/-}$mice. A, PCR analysis of CaBP1 and caldendrin transcripts. PCR amplification of both S-CaBP1/L-CaBP1 variants or caldendrin using RNA from Cabp $1^{+/+}$or Cabp $1^{-/-}$ mouse retinas. PCR amplification in the absence of DNA (-) was used as a negative control, and amplification of GAPDH was the positive control. $\boldsymbol{B}$, Analysis of CaBP1/CD proteins using immunohistochemistry. Immunolocalization of CaBP1/CD in the retinas of 2-month-old Cabp $1^{+/+}$and Cabp $1^{-/-}$mice using rat anti-CaBP1/CD antibodies. Nuclei are labeled with Hoechst. Lack of CaBP1/CD immunoreactivity confirms targeting of the Cabp1 gene. Scale bar: $20 \mu \mathrm{m}$. C, PCR analysis of CaBP2 transcripts. PCR amplification of both S-CaBP2/L-CaBP2 variants from Cabp2 $2^{+/+}$or $\mathrm{Cabp}^{-/-}$mouse retina. Controls as described in $\boldsymbol{A}$. $\boldsymbol{D}$, Analysis of CaBP2 proteins using immunohistochemistry. Immunolocalization of CaBP2 in the retina of 2-month-old Cabp2 $2^{+/+}, \mathrm{Cabp2}^{-/-}, \mathrm{Cabp}^{-/-}$, and $\mathrm{Cabp} 1^{-/-} / \mathrm{Cabp}^{-/-}$mice using rat anti-CaBP2 antibodies. Nuclei are labeled with Hoechst. Cross-reactivity of anti-CaBP2 antibody is revealed by labeling of $C a b p 2^{-/-}$mouse retina with this antibody and results in staining signals in the inner retina of Cabp2 ${ }^{-/-}$retina. The absence of staining in $\mathrm{Cabp} 1^{-1-} / \mathrm{Cabp}^{-/-}$double-KO mice demonstrates that the cross-reactivity of anti-CaBP2 antibodies is against the CaBP1/CD proteins. Specific labeling of CaBP2 in the inner retina is revealed by labeling of Cabp $1^{-/-}$mouse retina with anti-CaBP2 antibodies. Scale bar: $20 \mu \mathrm{m}$. 

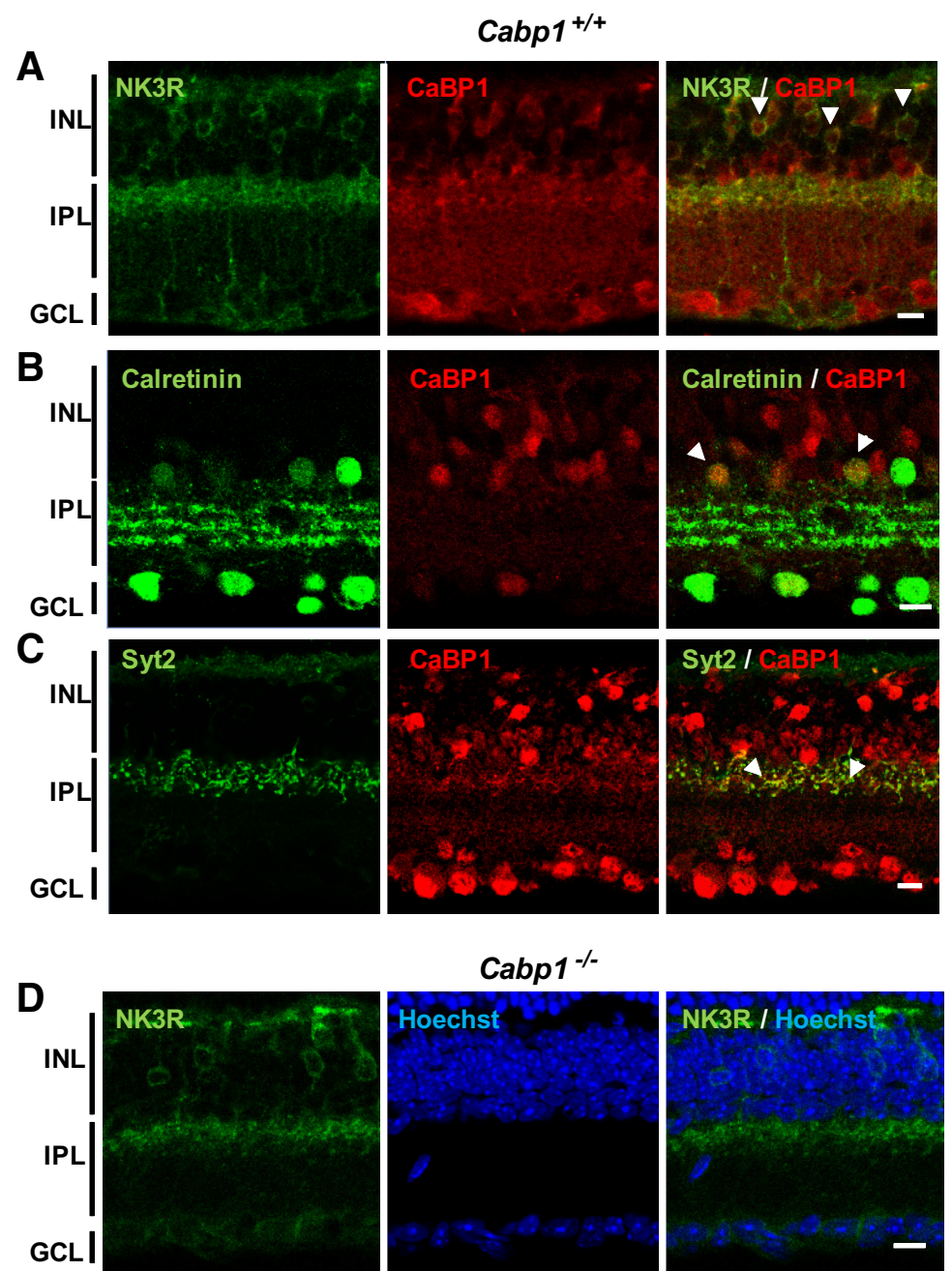

\section{Cabp $1^{-/}$}
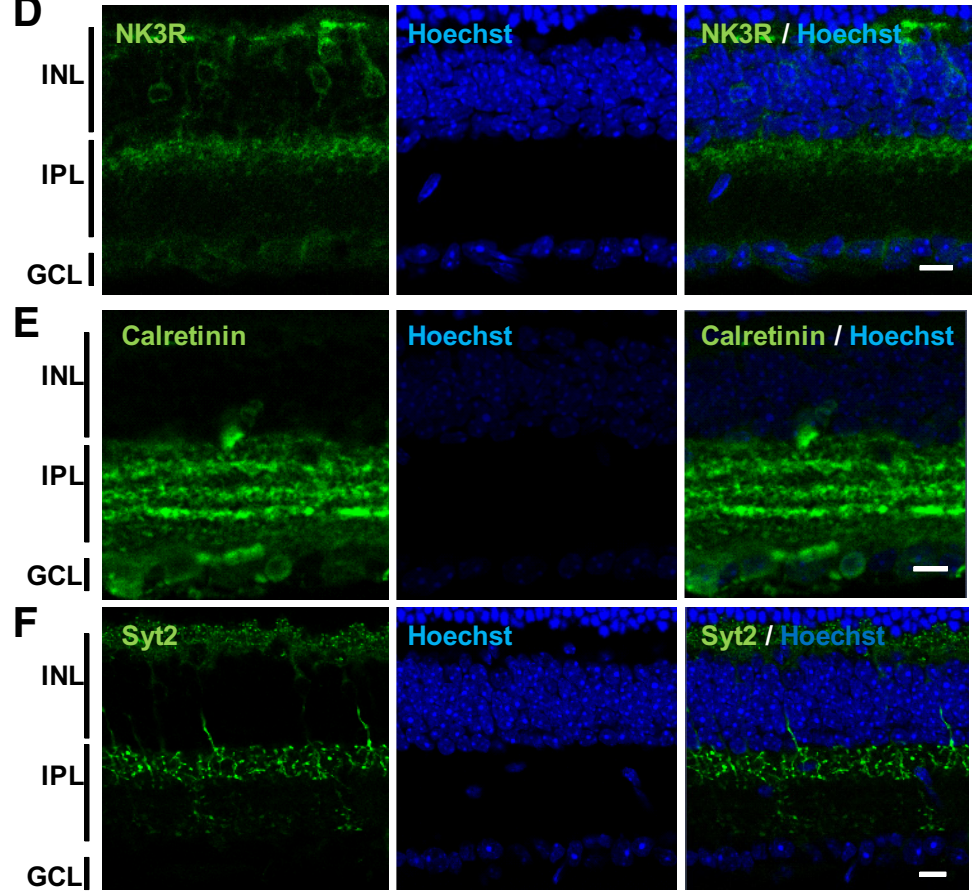

Figure 3. Analysis of the CaBP1/CD-expressing cells in Cabp $1^{+/+}$and Cabp $1^{-/}$mice. A, CaBP1/CD localizes in cells expressing NK3R in the inner retina. Analysis of $C a b p 1^{+/+}$mouse retina labeled with anti-NK3R (green) and rat anti-CaBP1/CD (red) using confocal microscopy. All cells labeled with anti-NK3R are also stained with anti-CaBP1/CD. Arrows in the right panels point to some of the yellow colocalization signals. INL, inner nuclear layer; GCL, ganglion cell layer. $\boldsymbol{B}, \mathrm{CaBP} 1 / \mathrm{CD}$ localizes in many cells expressing calretinin in the inner retina of $\mathrm{Cabp} 1^{+/+}$mouse retina. Legend as in $\boldsymbol{A}$ with anti-calretinin (green). $\boldsymbol{C}, \mathrm{CaBP} 1 / \mathrm{CD}$ colocalizes with synaptotagmin 2 in the outer IPL. Legend as in $\boldsymbol{A}$ with anti-Syt2 (green). $\boldsymbol{D}-\boldsymbol{F}$, Morphology of CaBP1/CD-deficient cells (NK3R stained type 1 and 2 bipolar cells, calretinin-stained amacrine cells, and Syt2-stained type 2 bipolar cells) is normal in Cabp $1^{-/-}$mouse retina. Scale bars: $10 \mu \mathrm{m}$. 
Table 1. Identified CaBP1/CD- or CaBP2-expressing cell types in the mouse retina.

\begin{tabular}{lll}
\hline Cell type/marker & CaBP1 & CaBP2 \\
OFF type $1 \mathrm{BP} / \mathrm{NK} 3 \mathrm{R}$ & + & + \\
OFF type $2 \mathrm{BP} / \mathrm{NK} 3 \mathrm{R}$ and Syt2 & + & \\
OFF type $3 \mathrm{BP}$ (3a and 3b)/CaBP5 & \\
OFF type $4 \mathrm{BP} /$ calsenilin & \\
ON type $5 \mathrm{BP} / \mathrm{CaBP5}$ & \\
ON type $6 \mathrm{BP} / \mathrm{Syt} 2$ & \\
ON type $7 \mathrm{BP} /$ gustducin-GFP & \\
Rod BP/CaBP5 & \\
Amacrine cells/calretinin & +
\end{tabular}

Retinal cell types tested for the expression of CaBP1 and CaBP2 and labeled with the indicated markers.

the bipolar cell types that express CaBP2, we used antibodies against selective markers. Double-labeling experiments with antibodies against CaBP2 and CaBP5 (Fig. $5 A-C)$ demonstrated that CaBP2 does not localize in bipolar cells expressing $\mathrm{CaBP} 5$, indicating that $\mathrm{CaBP} 2$ is not expressed in type 3 OFF, type $5 \mathrm{ON}$, and rod bipolar cells (Haeseleer et al., 2000; Ghosh et al., 2004). CaBP2 is also not expressed in anti-calsenilin-labeled type 4 OFF cone bipolar cells (Fig. 5D-F; Haverkamp et al., 2008). Gustducin-GFP mice express GFP in type 7 ON cone bipolar cells (Lin and Masland, 2005). Although our antiCaBP2 antibody would cross-react with CaBP1/CD in gustducin-GFP retinas, none of the GFP-labeled cells in these mice were labeled with anti-CaBP2 (Fig. 5G-l). We can thus conclude that type $7 \mathrm{ON}$ bipolar cells do not express CaBP1 and CaBP2 proteins.

To visualize the sublaminae of the inner plexiform layer, we labeled the mouse retina with an antibody to calretinin that displays a laminar pattern in three layers of the IPL separating sublaminae 1/2, 2/3, and 3/4 (Wässle, 2004; Fig. 6C) . Colabeling with anti-CaBP2 and anti-calretinin revealed that CaBP2 localizes in cells with axons in sublamina 1 and sublamina 3/4 (Fig. 6C). A partial overlap of the distribution of CaBP2 with NK3R indicated that either type 1 or type 2 OFF bipolar cells express CaBP2 (Fig. $6 A)$. Costaining with anti-Syt2 and anti-CaBP2 antibodies showed colocalization of Syt 2 and CaBP2 in sublaminae $3 / 4$ but not in sublamina 1 (Fig. 6B). This result indicates that CaBP2 is expressed in type 6 ON bipolar cells. We can also conclude from Syt 2 and NK3R labeling experiments that type 1 OFF bipolar cells express CaBP2 (Table 1). Although CaBP2 showed colocalization with Syt2 in sublamina 3/4, additional CaBP2-labeled cells appeared to have their axon arborization extending in sublamina 3/4. Because of the lack of other markers for these bipolar cells, it was not possible to identify these CaBP2-expressing cells.

\section{Analysis of retinal morphology in $\mathrm{Cabp2}^{-/-}$mice}

To determine whether CaBP2 is necessary for normal retinal development and structure, we analyzed the morphology of the CaBP2-deficient cells using antibodies against Syt2 and NK3R to look at type 6 ON and type 1 OFF bipolar cells. Overall morphology of these bipolar cells and thickness of the retinal layers did not differ noticeably between $\mathrm{Cabp}^{+/+}$and $\mathrm{Cabp2}^{-/-}$retinas (Fig. 6). The Syt2-labeled axons of type 6 ON bipolar cells in the inner IPL and NK3R-labeled axons of OFF bipolar cells in the outer IPL showed normal morphology (Fig. 7). No difference was observed in the OPL between the Syt2labeled dendrites of $\mathrm{Cabp2}^{+/+}$and $\mathrm{Cabp2}^{-/-}$retinas. There were also no apparent changes in the number of synapses visualized with anti-Ctbp2 in $\mathrm{Cabp}^{-/-}$mice (Table 2). Normal synaptic ribbons and tethered vesicles were observed in both IPL and OPL of $\mathrm{Cabp2}^{+/+}$and $C a b p 2^{-/-}$retinas using electron microscopy (Fig. 7B, D). Cone bipolar cell and horizontal cell invaginations appeared to make a normal synapse with cone photoreceptors (Fig. 7D).

\section{Altered light responses of ganglion cells in Cabp1 $1^{-/-}$ and $\mathrm{Cabp2}^{-1-}$ mice}

To determine whether CaBP1/CD and CaBP2 are important for retinal function, we measured ganglion cell responses to full-field light stimuli. We selected three well-characterized mouse ganglion cell types: ON-alpha, OFF transient (OFF T), and OFF sustained (OFF S). Extensive work on these alpha-like ganglion cells has identified type-specific response properties generated from distinct circuit mechanisms (Pang et al., 2003; Murphy and Rieke, 2006; van Wyk et al., 2009; Schwartz et al., 2012). Recordings were performed at a background of $900 \mathrm{R} * / \mathrm{S}$ cone/s, where cones dominate retinal responses.

Because CaBP2 is expressed in type 6 bipolar cells, and because $\mathrm{ON}$ alpha ganglion cells receive most excitatory synaptic input from this bipolar cell type (Morgan et al., 2011; Schwartz et al., 2012), we chose ON alphas as the primary candidate for studying perturbation in ganglion cell function in $\mathrm{Cabp2}^{-/-}$retinas (Fig. 8). Responses to a $100 \%$ contrast light flash were significantly smaller in mice lacking CaBP2 (Fig. 8C, D).

We characterized the response kinetics and contrast sensitivity using linear-nonlinear models computed from excitatory synaptic currents in response to a random noise stimulus (Chichilnisky, 2001; Kim and Rieke, 2001; Rieke, 2001). This model provides a relatively simple description of how continuous light inputs are transformed into cellular responses and provides an effective means of characterizing contrast-dependent changes in the amplitude and kinetics of the light response of a cell. The model consists of a linear filter that accounts for the time course of the response and a time-independent or "static" nonlinearity that converts the filtered stimulus into responses (excitatory synaptic currents; Fig. 8).

The linear filters of $\mathrm{ON}$ alpha ganglion cells were slightly slower in Cabp2 ${ }^{-/}$retinas compared with control retinas (Fig. 8F, G). The nonlinearities were strikingly different between the $\mathrm{ON}$ alpha ganglion cells of $\mathrm{Cabp}^{+/+}$and $\mathrm{Cabp2}^{-/-}$retinas (Fig. $8 \mathrm{H}, \mathrm{I}$ ).

The response range of the responses-i.e., the difference between the maximum and minimum excitatory synaptic current evoked by the random noise stimulus-was significantly smaller for $\mathrm{ON}$ alpha ganglion cells in $\mathrm{Cabp2}^{-1-}$ retinas compared with control cells (Fig. $8 \mathrm{H}, I$ ). 
A
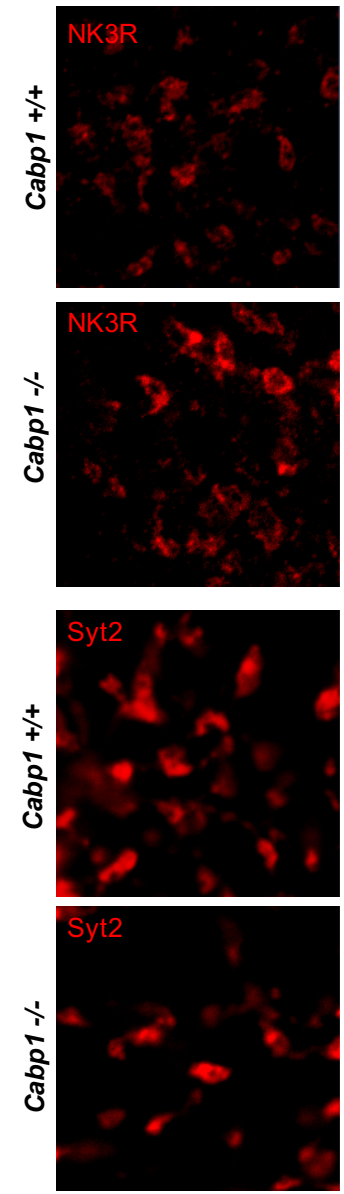

C
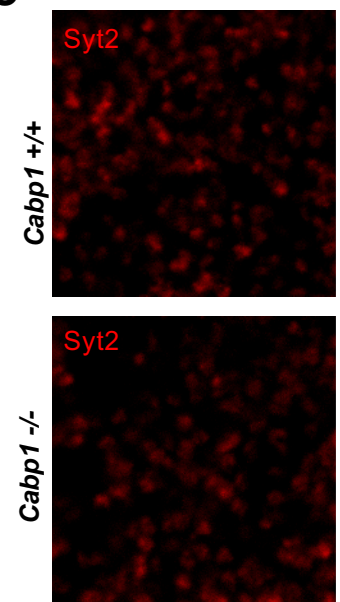

outer IPL
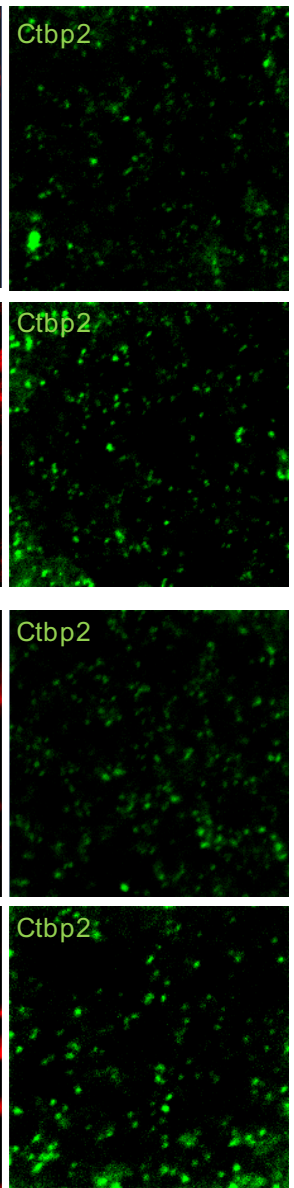

OPL
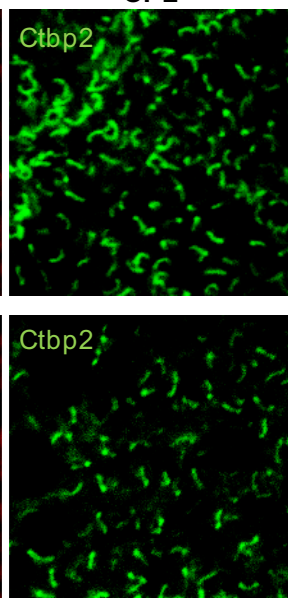
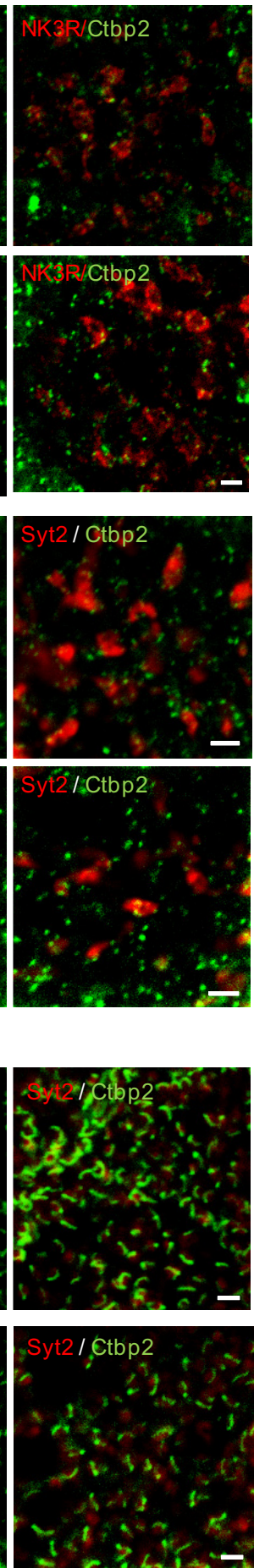

B
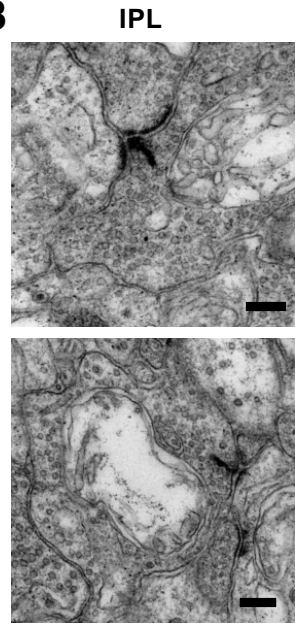

D
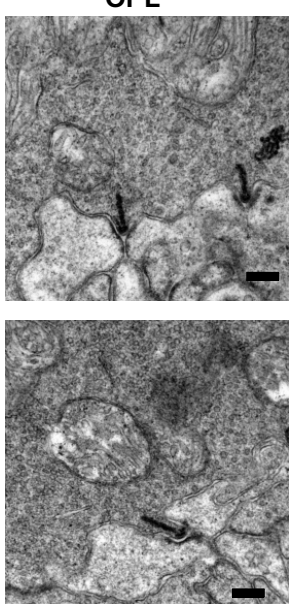

Figure 4. Ribbon synapse morphology in the OPL and IPL of Cabp $1^{+/+}$and Cabp $1^{-/-}$mice. A, Confocal images showing en face views of the axon terminals of Syt2-labeled type 2 cone OFF bipolar cells (selected in IPL outer sublamina) or NK3R-labeled type 1 and 2 cone OFF bipolar cells in Cabp $1^{+/+}$and Cabp $1^{-/-}$retina whole mounts. Synaptic ribbons were visualized with anti-Ctbp2 (green). The axons and ribbons appear normal in both Cabp $1^{+/+}$and Cabp $1^{-/-}$retinas. Scale bar: $2 \mu \mathrm{m}$. B, Representative electron micrographs of cone OFF bipolar cells in mouse retina cross-sections through the IPL within $5 \mu \mathrm{m}$ from the inner nuclear layer. Normal ribbons and tethered vesicles are observed both in Cabp $1^{+/+}$and Cabp $1^{-/-}$retinas. Scale bar: $200 \mathrm{~nm}$. C, En face views of the dendrites of type 2 cone OFF and type 6 cone ON bipolar cells in the OPL of mouse retina whole mounts labeled with anti-Syt2 (red) and anti-Ctbp2 (green). Scale bar: $2 \mu \mathrm{m}$. $\boldsymbol{D}$, Representative electron micrographs of mouse retina cross-sections through the OPL. Scale bar: $200 \mathrm{~nm}$. 
Table 2. Quantification of Ctbp2-labeled ribbons.

\begin{tabular}{|c|c|c|c|c|c|c|}
\hline \multirow[b]{2}{*}{ Type } & \multicolumn{6}{|c|}{ Number/25 $\mu \mathrm{m}^{2}$} \\
\hline & Ribbons in OPL & $p$-value & $\begin{array}{c}\text { Ribbons in NK3R-labeled } \\
\text { outer IPL }\end{array}$ & $p$-value & $\begin{array}{l}\text { Ribbons in Syt2-labeled } \\
\text { inner IPL }\end{array}$ & $p$-value \\
\hline WT & $8.58 \pm 0.30$ & 1 & $16.33 \pm 0.45$ & 1 & $13.33 \pm 0.42$ & 1 \\
\hline Cabp $1^{-/-}$ & $8.12 \pm 0.27$ & 0.26 & $16.04 \pm 0.49$ & 0.66 & $14.16 \pm 0.53$ & 0.22 \\
\hline Cabp2 $2^{-1-}$ & $8.25 \pm 0.21$ & 0.36 & $16.75 \pm 0.47$ & 0.53 & $14.54 \pm 0.53$ & 0.08 \\
\hline
\end{tabular}

Retinal whole mount, as shown in Figures 4 and 6, from four mice for each phenotype were analyzed by confocal microscopy. Ctbp2-labeled ribbons were counted in images of six areas of $25 \mu \mathrm{m}^{2}$ for each mouse in the OPL. Ctbp2-labeled puncta were also quantified in the NK3R-labeled sublamina containing type 1 and 2 OFF bipolar cell axon terminals or Syt2-labeled sublaminae of the inner IPL containing the type 6 ON bipolar cells. Numbers represent mean \pm SE $(n=24)$. Statistical comparisons with WT mice were performed using the Student's $t$-test.

Because CaBP1/CD is expressed in OFF bipolar cells, we analyzed responses of OFF $S$ and OFF T ganglion cells in $\mathrm{Cabp}^{1^{-1}}$ retinas. Differences in lamination of OFF S and OFF T ganglion cells in the IPL suggest that they derive their excitatory inputs from different OFF bipolar cells. Responses to a light flash were larger and slower for OFF $\mathrm{T}$ ganglion cells compared with control retinas. Responses of OFF S ganglion cells in Cabp $1^{-1-}$ retinas to a light flash exhibited no significant difference in amplitude with respect to control retinas (Fig. 9A, B). The response kinetics were slower for OFF $S$ and OFF T ganglion cells in $\mathrm{Cabp}^{-/-}$retinas compared with controls (Fig. 9A, B).
Nonlinearities were strikingly different between the OFF alpha ganglion cells from $\mathrm{Cabp}^{-/-}$and control retinas (Fig. 9A, B). The change in the nonlinearity was opposite for OFF $S$ and OFF T ganglion cells, with a smaller response range for $\mathrm{Cabp} 1^{-1-}$ OFF S ganglion cells and larger response range for $\mathrm{Cabp1}^{-/-}$OFF $\mathrm{T}$ ganglion cells. Changes in excitatory synaptic currents affect the spike output of the ganglion cells. Indeed, spike responses of ON alpha ganglion cell to a $100 \%$ contrast step were weaker in $\mathrm{Cabp2}^{-/-}$retinas than in control retinas (Fig. 10). Similarly, OFF T ganglion cells exhibited a stronger spike response in $\mathrm{Cabp1}^{-/-}$than in control retinas (Fig. 10).
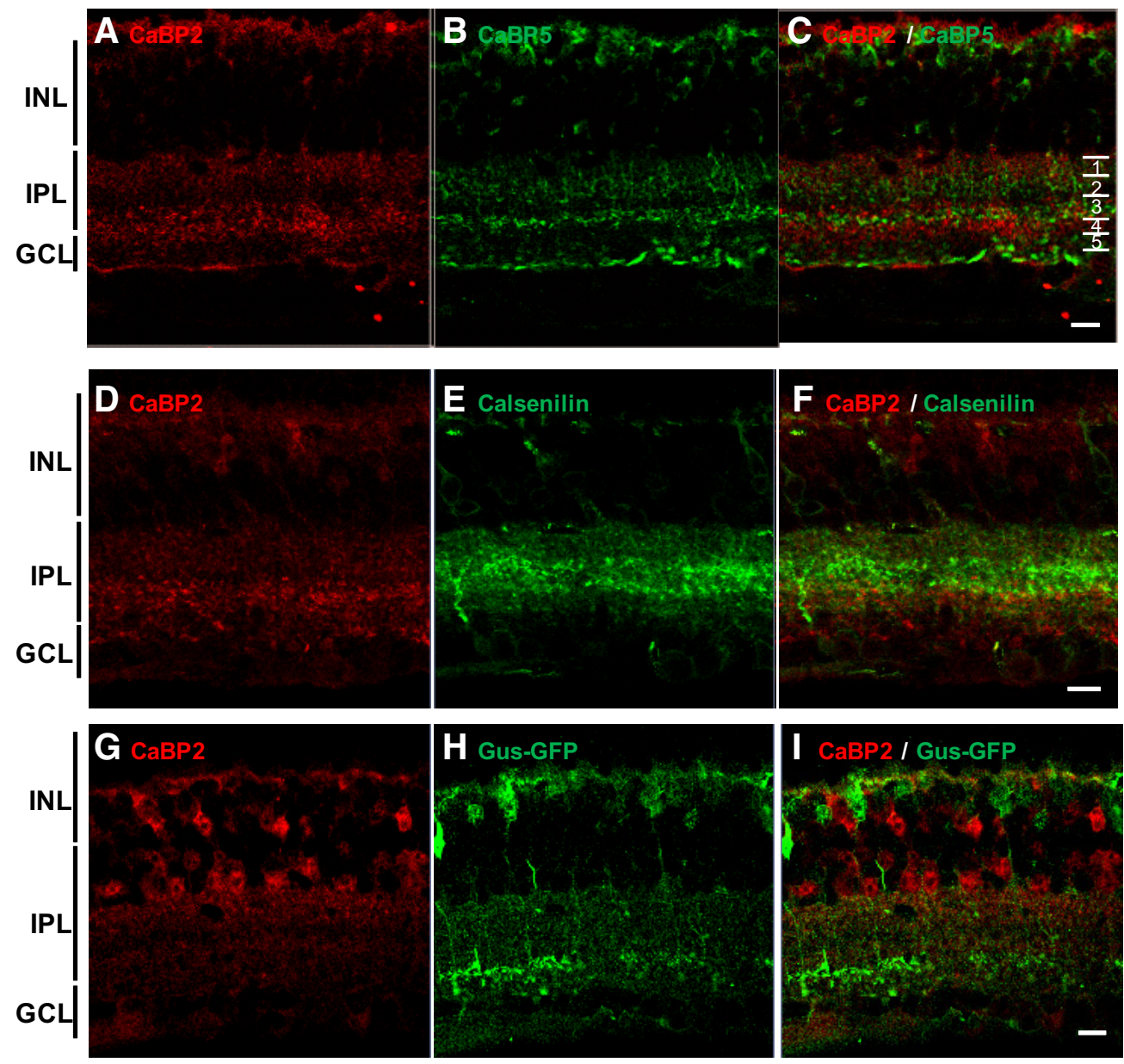

Figure 5. Immunolocalization of CaBP2 in mouse retina. Confocal images of Cabp1 $1^{-/}(\boldsymbol{A}-\boldsymbol{F})$ or Gus-GFP (G-I) mouse retinas double labeled for CaBP2 and CaBP5 $(\boldsymbol{A}-\boldsymbol{C})$, calsenilin $(\boldsymbol{D}-\boldsymbol{F})$, and GFP $(\boldsymbol{G}-\boldsymbol{I})$. Sublaminae 1-5 are indicated in $\boldsymbol{C}$. Scale bar: $10 \mu \mathrm{m}$. 
A

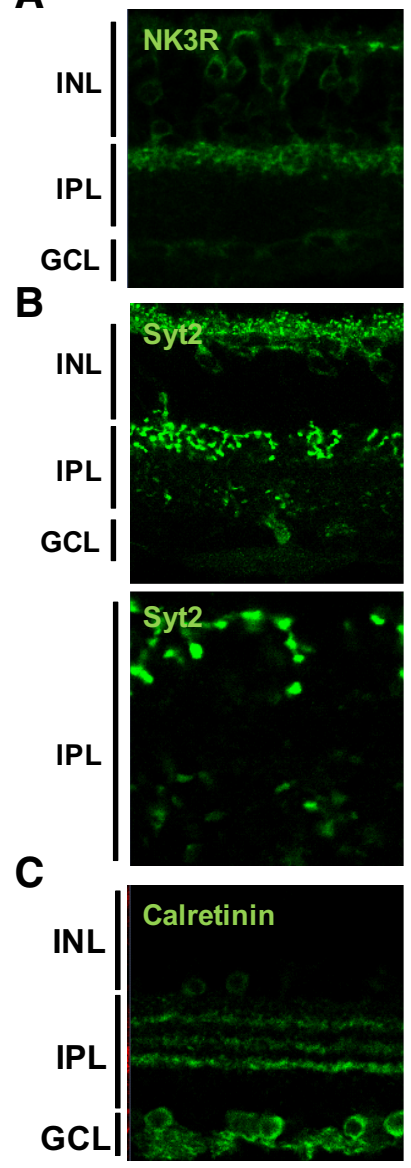

D

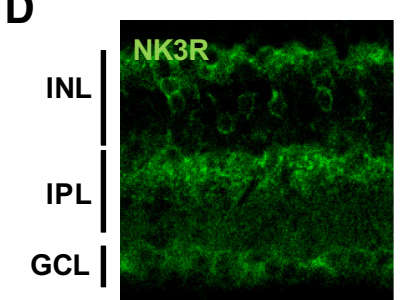

E

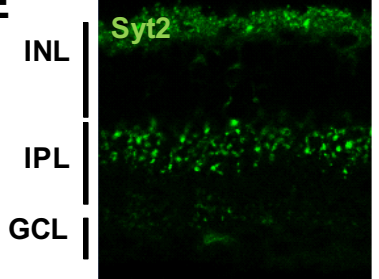

F

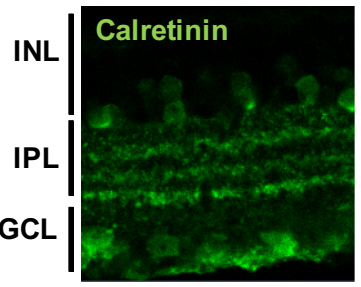

Cabp2 $^{+/+}$
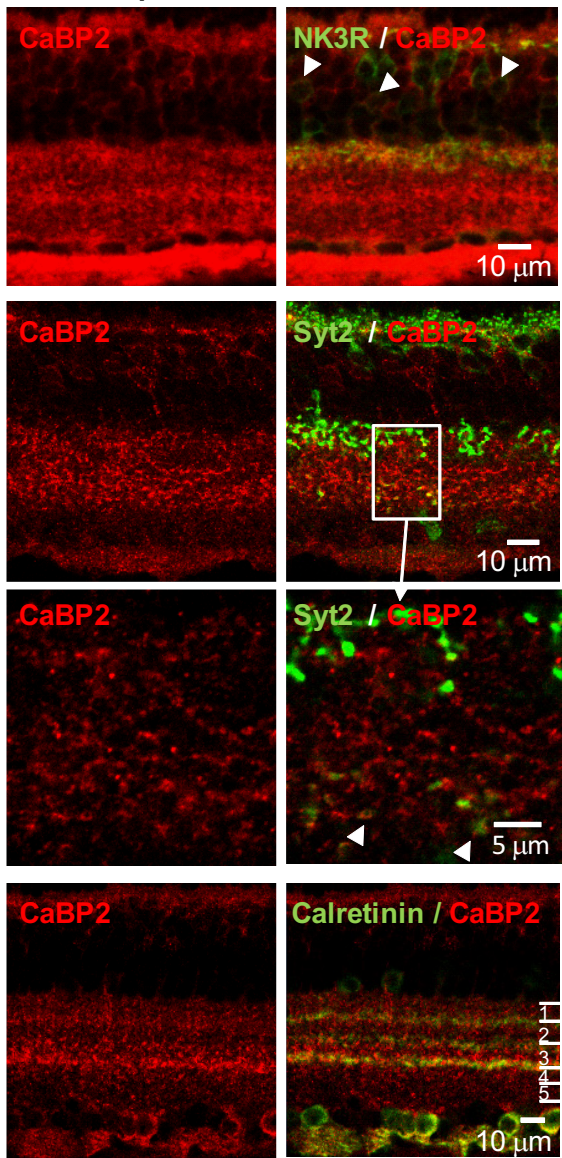

Cabp2 $\%$
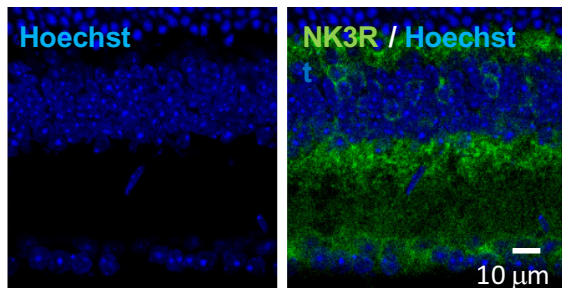

Hoechst

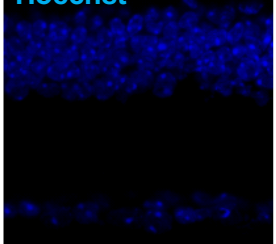

Syt2/Hoechst

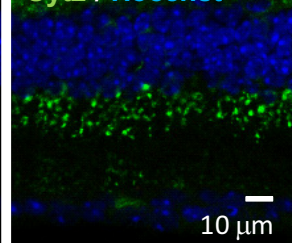

Hoechst

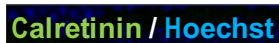

Calretinin / Hoechst
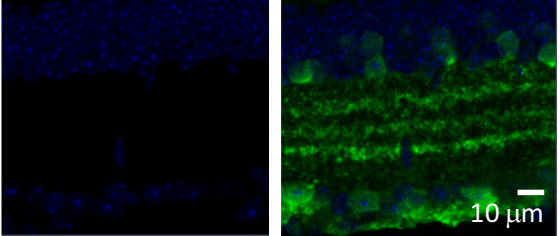

Figure 6. Analysis of the CaBP2-expressing cells in $\mathrm{Cabp2}^{+/+}$and $\mathrm{Cabp}^{-/-}$mice. $\boldsymbol{A}$, CaBP2 localizes in some cells expressing NK3R in the inner retina. Analysis of $\mathrm{Cabp2}^{+/+}$mouse retina labeled with anti-NK3R (green) and rat anti-CaBP2 (red) using confocal microscopy. Some cells labeled with anti-NK3R are also stained with anti-CaBP2. Arrows in the right panels point to some of the yellow colocalization signals. INL, inner nuclear layer; GCL, ganglion cell layer. B, CaBP2 localizes in some cells expressing 
continued

synaptotagmin 2 in the inner retina of $\mathrm{Cabp}^{+/+}$mice. Legend as in $\boldsymbol{A}$ with anti-Syt2 (green). The area shown at higher magnification in the bottom panels is indicated by the white box. $\mathbf{C}$, CaBP2-labeled cells terminate their axons in sublamina 1 and sublamina $3 / 4$. Legend as in $\boldsymbol{A}$ with anti-calretinin (green). Sublaminae 1-5 are indicated in the right panel. $\boldsymbol{D}-\boldsymbol{F}$, The overall morphology of the retina and CaBP2-deficient cells (NK3R- and synaptotagmin-labeled bipolar cells) is normal in Cabp2 ${ }^{-/-}$mouse retinas.

We also compared excitatory synaptic currents of ON alpha ganglion cells in Cabp $1^{-1-}$ retinas and OFF T ganglion cells in Cabp2 ${ }^{-/-}$retinas with corresponding control cells (Fig. 11). Responses of these cells could be affected, since CaBP1/CD is expressed in amacrine cells and CaBP2 is expressed in type 1 OFF bipolar cells. Interestingly, the response kinetics of the $\mathrm{ON}$ alpha ganglion cells were slower, but the response range was unchanged or slightly increased in $\mathrm{Cabp}^{-/-}$retinas, unlike in Cabp2 $2^{-/-}$ retinas (Fig. 11). The response kinetics of the OFF T ganglion cells and the response range of responses did not change significantly in Cabp2 ${ }^{-/}$retinas (Fig. 11).

\section{Discussion}

$\mathrm{Ca}^{2+}$-binding proteins modulate the cellular activities of enzymes, channels, and structural proteins in response to changes in intracellular $\left[\mathrm{Ca}^{2+}\right]$. Here, we determined whether the lack of $\mathrm{CaBP} 1 / \mathrm{CD}$ or $\mathrm{CaBP} 2$, neuronal calcium binding proteins expressed in distinct retinal secondary neurons, results in altered transmission of light responses through the retina. We found that not only the kinetics but also the amplitude and response range of the light responses in ganglion cells are affected in the $a b-$ sence of $\mathrm{CaBP} 1 / \mathrm{CD}$ or $\mathrm{CaBP} 2$, whereas the overall morphology of the CaBP1/CD- or CaBP2-deficient retina and synapses is not affected. These findings give a first insight into the importance of CaBP1/CD and CaBP2 for normal visual function.

\section{CaBP2 is expressed in cone ON and OFF bipolar cells}

Our immunohistochemistry results showed that CaBP2 is expressed in type 1 cone OFF bipolar and type 6 cone ON bipolar cells. Type 1 cone ON bipolar cells are the first retinal neurons to date shown to express two different CaBPs, CaBP2, and CaBP1/CD (Figs. 3 and 6; Haverkamp et al., 2003a), since CaBPs were previously shown to be expressed in distinct neurons (Haeseleer et al., 2000, 2004; Haverkamp et al., 2003a; Ghosh et al., 2004). This raises the question of whether CaBP1/CD and CaBP2 might modulate different targets and/or have a different effect on the same target in type 1 cone OFF bipolar cells. In addition to type 1 and type 6 cone bipolar cells, other cells of the inner nuclear layers in sublamina $3 / 4$ appeared to be immunostained with anti-CaBP2 antibody. Although we cannot exclude that type 8 and type 9 bipolar cells might express CaBP2, the axons of those cell types have been described to stratify in S4,S5 (Ghosh et al., 2004) rather than S3,S4 as observed for the CaBP2labeled cells. Still, type 8 bipolar cells appeared to stratify broadly with the Syt2-labeled type 6 bipolar cells (Dunn and Wong, 2012). These unidentified CaBP2-labeled cells looked rather similar to the CB3,4 cells previously visualized using gene gun labeling and displaying a broad axonal arbor that extends through layers 3 and 4 (Pignatelli and Strettoi, 2004).

\section{Retinal morphology of Cabp $1^{-/-}$and $\mathrm{Cabp2}^{-/-}$mice is normal}

Immunohistochemistry analysis of $\mathrm{Cabp1}^{-/}$and Cabp2 $2^{-/-}$mouse retinas using specific markers showed no changes in the cell, dendritic, and axon morphologies of cells deficient for CaBP1/CD or CaBP2. Analysis of synapses by immunostaining with Ctbp2 or electron microscopy did not reveal changes in the morphology or density of synaptic ribbons or tethered synaptic vesicles. This suggests that $\mathrm{CaBP} 1 / \mathrm{CD}$ and $\mathrm{CaBP} 2$ are not essential for the development and maintenance of a normal synapse or the docking of synaptic vesicles. Similar results were obtained for CaBP5 KO mice. As for Cabp $1^{-/-}$ and $\mathrm{Cabp}^{-/-}$mouse retinas, no significant changes in the number of synaptic vesicles or docked synaptic vesicles was observed in $\mathrm{Cabp5}^{-/}$mouse retina (Rieke et al., 2008). However, CaBP5 was shown to stimulate synaptic vesicle exocytosis (Sokal and Haeseleer, 2011). It is thus possible that $\mathrm{CaBP} 1 / \mathrm{CD}$ and $\mathrm{CaBP} 2$ play a role in neurotransmitter release by regulating events beyond vesicle docking.

\section{Kinetics and amplitude of ganglion cell responses are affected in Cabp1 $1^{-/}$and Cabp2 $2^{-/-}$mice}

We investigated the light responses of alpha ganglion cells to determine the importance of CaBP1/CD and CaBP2 for proper transmission of light responses across the retina. Compared with responses of ganglion cells from WT retina, we observed a $\sim 50 \%$ increase in the amplitude of the excitatory postsynaptic currents of OFF $\mathrm{T}$ ganglion cells of $\mathrm{Cabp} 1^{-/-}$mice and a $\sim 60 \%$ decrease of the excitatory synaptic currents in $\mathrm{ON}$-alpha ganglion cells of $\mathrm{Cabp2}^{-/-}$mice. Because CaBP1/CD and CaBP2 are expressed throughout bipolar cells, it is possible that these altered responses originate from a defect in the processing of the light signal received from cones. Such a defect at the cone-to-cone bipolar cell synapse should affect the electroretinograms of $\mathrm{Cabp}^{-/-}$and $\mathrm{Cabp2} 2^{-/-}$ mice. However, the time to peak and amplitude of b-waves of electroretinograms of Cabp $1^{-/-}$and Cabp2 $2^{-/-}$ mice did not differ significantly from those of WT mice (data not shown); this suggests that alterations in the transmission of the light signal likely occur downstream of the bipolar cell dendrites.

Interestingly, the two OFF alpha ganglion cell types displayed similar changes in kinetics but opposite changes in response range in Cabp $1^{-/-}$mice. The opposite changes in response range could be explained if the bipolar cells that provide input to OFF $S$ and OFF T ganglion cells express different targets for CaBP1/CD. 
A
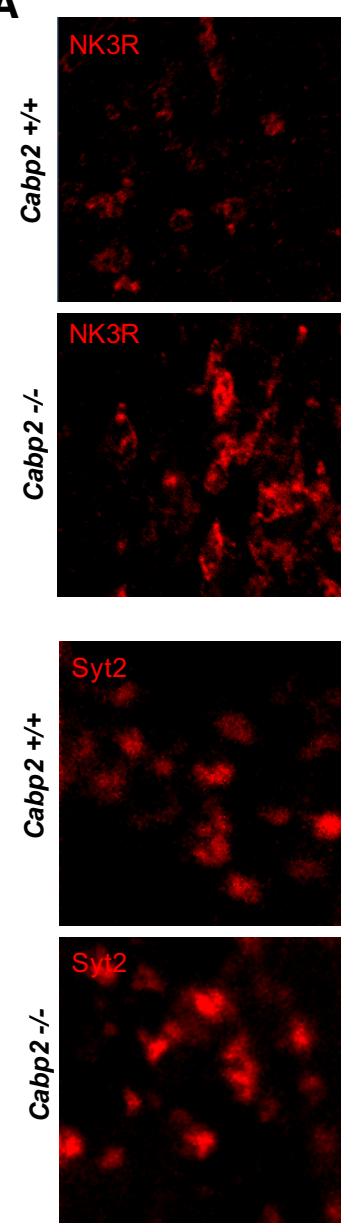

C
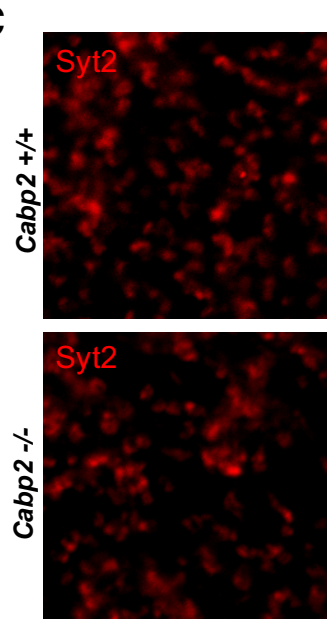

outer IPL
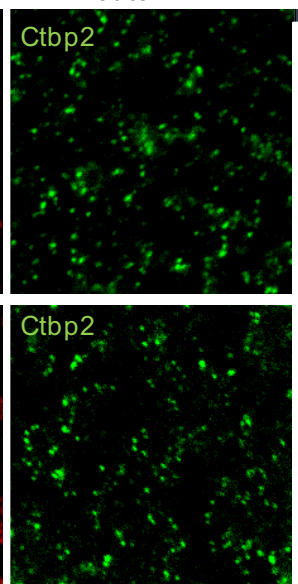

inner IPL
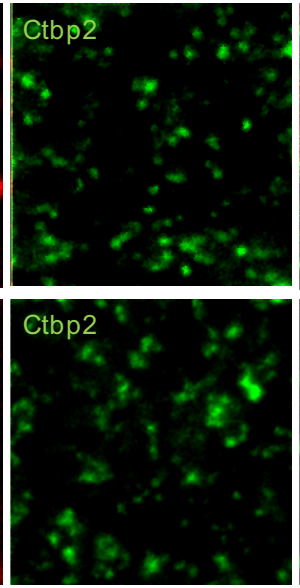

OPL
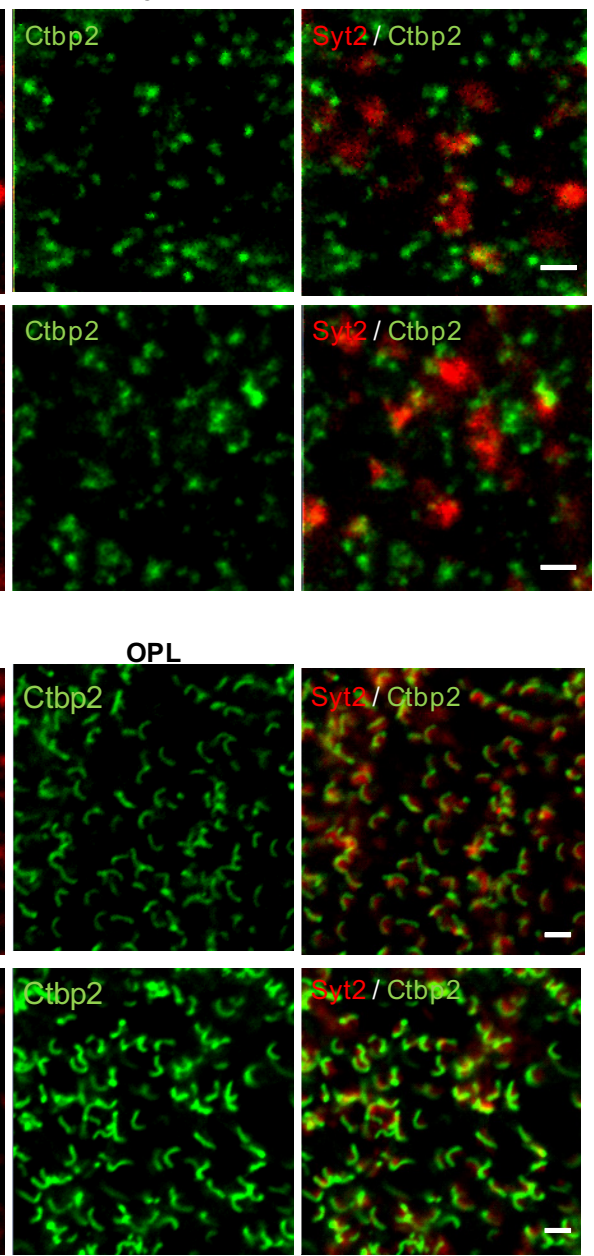

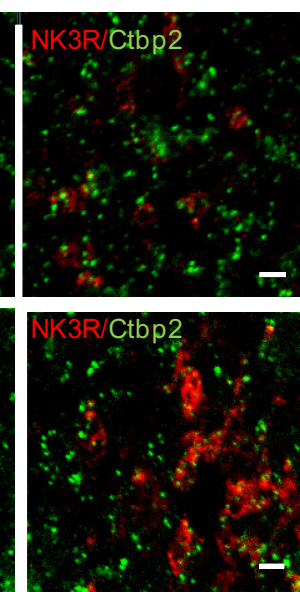

B
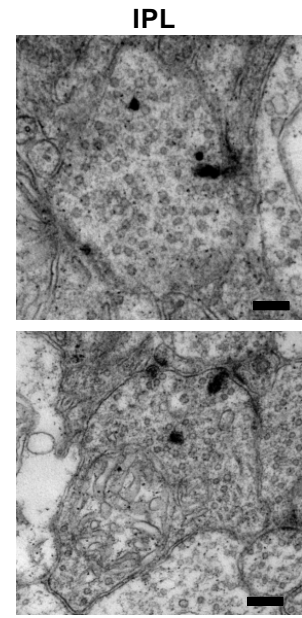

D
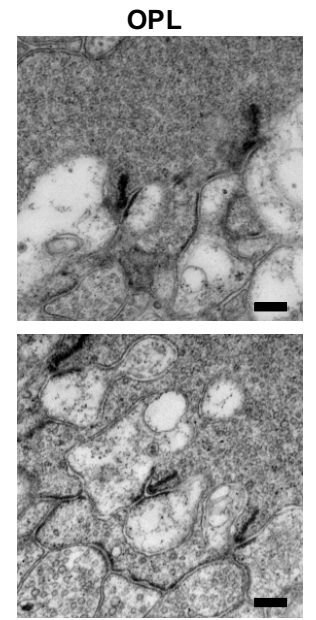

Figure 7. Ribbon synapse morphology in the OPL and IPL of Cabp2 $2^{+/+}$and Cabp2 $2^{-1-}$ mice. A, Confocal images of en face views of the axon terminals of Syt2-labeled type 6 cone ON bipolar cells (selected in IPL inner lamina) or NK3R-labeled cone OFF bipolar cells in $\mathrm{Cabp2}^{+/+}$and $\mathrm{Cabp2}^{-/}$retina whole mounts. Synaptic ribbons were visualized with anti-Ctbp2 (green). The axons and ribbons of $\mathrm{Cabp2}^{+/+}$and $\mathrm{Cabp}^{-/-}$retinas appear similar. Scale bar: $2 \mu \mathrm{m}$. B. Representative electron micrographs of cone OFF bipolar cells in mouse retina cross-sections through the IPL within $2 \mu \mathrm{m}$ from the inner nuclear layer. Scale bar: $200 \mathrm{~nm}$. $\boldsymbol{C}$, En face views of the dendrites of type 2 cone OFF and type 6 cone ON bipolar cells in the OPL of mouse retina whole mounts labeled with anti-Syt2 (red) or anti-Ctbp2 (green). Scale bar: $2 \mu \mathrm{m}$. $\boldsymbol{D}$, Representative electron micrographs of cone terminals in mouse retina cross-sections through the OPL. Scale bar: $200 \mathrm{~nm}$. 
A

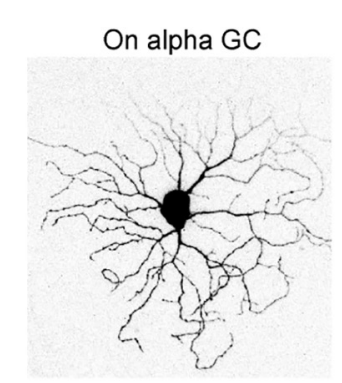

B

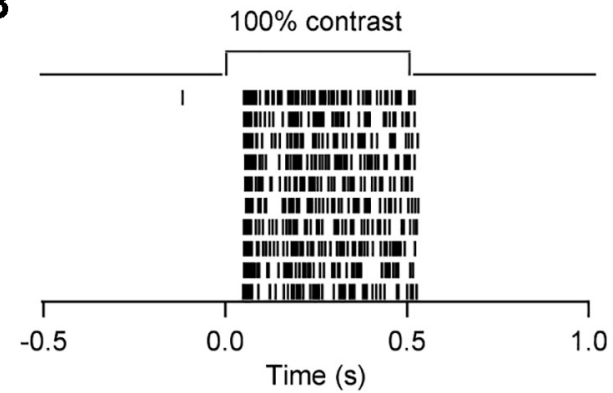

C
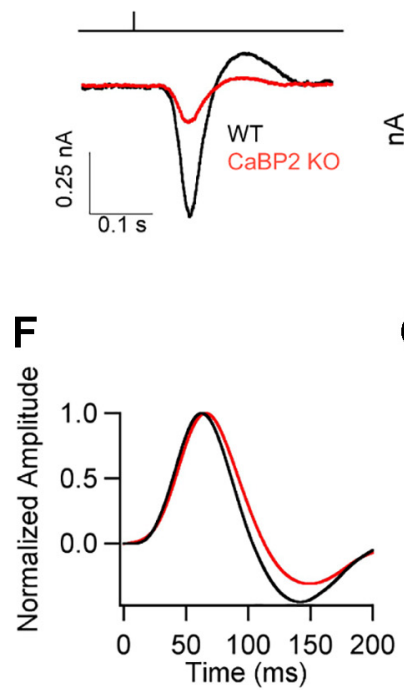

D

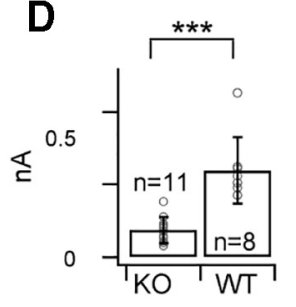

E

G

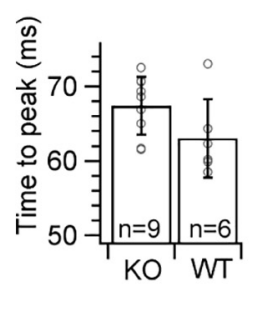

H

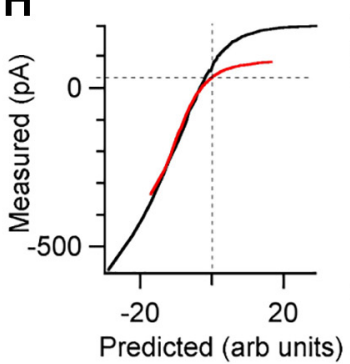

I

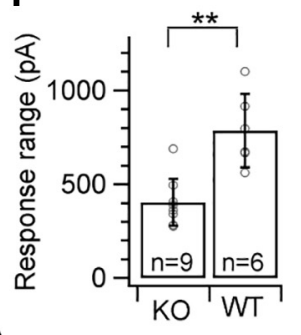

Figure 8. ON alpha ganglion cell responses in Cabp2 $2^{+/+}$and $\mathrm{Cabp} 2^{-/-}$mice. A, Maximum-projection image of an exemplar ON alpha ganglion cell filled with dye postrecording. B, Exemplar spike raster from an ON alpha ganglion cell in response to $100 \%$ contrast step. C, Average excitatory synaptic currents in response to $10-\mathrm{ms}$ flash of $100 \%$ contrast. $\boldsymbol{D}$, Bar graph comparing the peak amplitude of synaptic response shown in $\boldsymbol{C}$ across all cells between control and Cabp $2^{-/-}$. $\boldsymbol{E}$, Linear-nonlinear (LN) model: a time-varying random stimulus and the resulting ganglion cell excitatory synaptic inputs were used to derive the linear filter and static nonlinearity that relate the stimulus to the response (top). $\boldsymbol{F}$, Average normalized linear filters for the stimuli. G, Quantification of the time to peak, i.e., latency of the peaks in linear filters. $\boldsymbol{H}$, Nonlinearities of ganglion cells for the noise stimuli. $\boldsymbol{I}$, Quantification of the response range of the measured response across all cells.

Alternatively, CaBP1 may differently shape the synaptic input to these two types of OFF ganglions cells.

The absence of CaBP2 resulted in a decrease in the response range of the $\mathrm{ON}$ alpha ganglion cell response. The absence of CaBP1/CD slowed response kinetics but did not change the response range of the excitatory synaptic currents of the $\mathrm{ON}$ alpha ganglion cells. Because CaBP1 is not found in cone ON bipolar cells, the effect of CaBP1 deficiency on ON alpha ganglion cell excitatory inputs could result from alterations in responses of amacrine cells that provide presynaptic inhibition on type 6 bipolar cells and shape the kinetics of excitatory inputs of ON alpha ganglion cells. The complex interplay between ON and OFF pathways means that other explanations are possible as well.

Although CaBP2 deficiency results in decreased amplitude of the excitatory synaptic currents in ON alpha ganglion cells (Fig. 8), the lack of CaBP1/CD causes an increase of OFF ganglion cell responses (Fig. 9). This opposite effect on the amplitude of ganglion cell responses suggests that CaBPs may have different targets in different cell types or opposing effects on similar targets. Prominent targets of CaBPs, including CaBP1 and CaBP2, are the voltage-gated $\mathrm{Ca}^{2+}$ channels (Lee et al., 2002; Haeseleer et al., 2004; Zhou et al., 2004; Cui et al., 2007; Rieke et al., 2008; Schrauwen et al., 2012). Voltagegated $\mathrm{Ca}^{2+}$ channels are directly involved in vesicle exocytosis and are a possible target for CaBP1/CD and CaBP2 in bipolar cells and amacrine cells (Pan et al., 2001; Habermann et al., 2003; Singer and Diamond, 2003; Balakrishnan et al., 2015). Specifically for CaBP1, it was shown that CaBP1 has opposite effects depending on the type of voltage-gated $\mathrm{Ca}^{2+}$ channels it modulates (Haeseleer et al., 2000; Lee et al., 2002; Zhou et al., 2004; Cui et al., 2007). Because CaBPs can both inhibit or activate voltage-gated calcium channels, it might concomitantly decrease or increase synaptic vesicle release. Using electrophysiological recordings, cone bipolar cells have been shown to express diverse $\mathrm{Ca}_{\mathrm{v}}$ channels, including $\mathrm{Ca}_{\mathrm{v}} 1$ (L-type) and $\mathrm{Ca}_{\mathrm{v}} 3$ (T-type; Kaneko et al., 1989; Pan, 2000; Pan et al., 2001). T-type $\mathrm{Ca}^{2+}$ channels have not been shown to be modulated by calmodulin or calmodulin-like 
A

(i)

(ii)

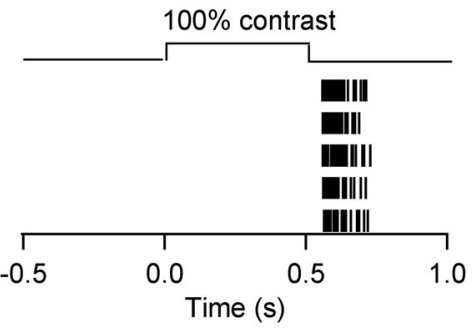

(iii)

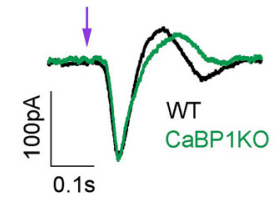

(iv)

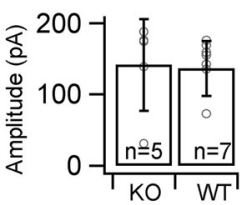

(v)

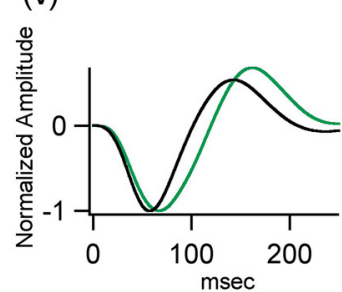

(vii)

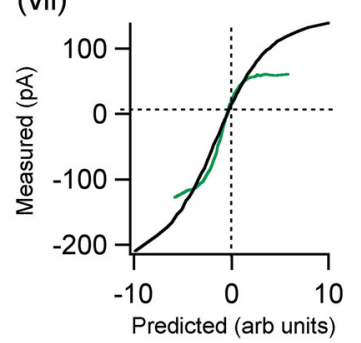

(viii)
B

(i)

(ii)

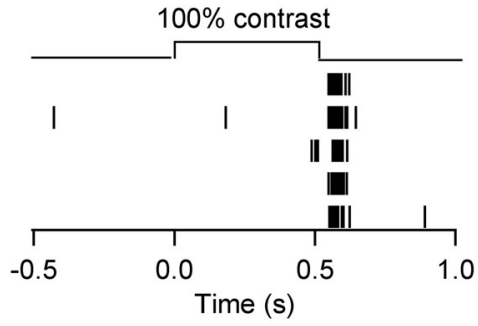

(iii)
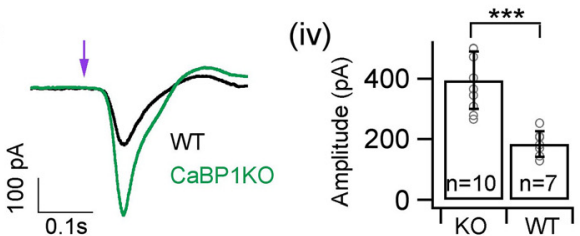

(v)
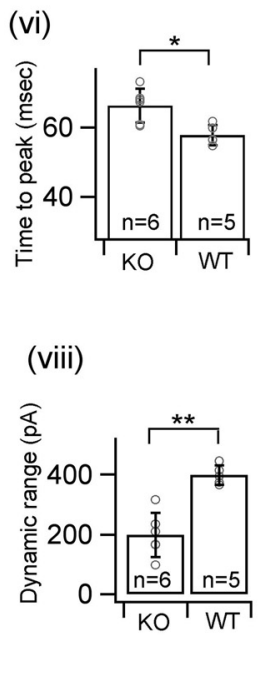

OFF transient GC

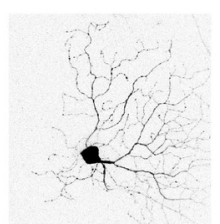

$100 \%$ contrast

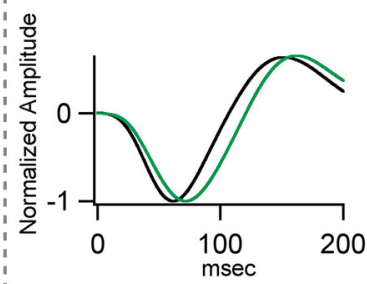

(vi)

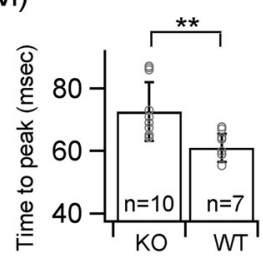

(vii)

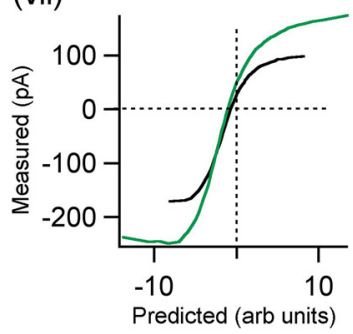

(viii)

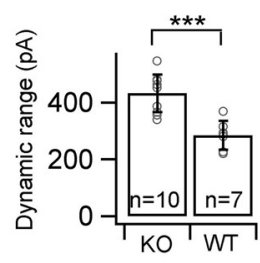

Figure 9. OFF alpha ganglion cell responses in Cabp $1^{+/+}$and Cabp $1^{-/-}$mice. $\boldsymbol{A}, \boldsymbol{B}$ (i), Maximum projection image of an exemplar OFF sustained and OFF transient alpha ganglion cell filled with dye postrecording. $\boldsymbol{A}, \boldsymbol{B}$ (ii), Exemplar spike raster in response to $100 \%$ contrast step. A, B (iii), Average excitatory synaptic currents in response to a 10-ms flash of $100 \%$ contrast from control and Cabp $1^{-/-}$ retinas. $\boldsymbol{A}, \boldsymbol{B}$ (iv), Quantification of the peak amplitude of synaptic response shown in iii across all cells between control and Cabp $1^{-/-}$ retinas. $\boldsymbol{A}, \boldsymbol{B}(\boldsymbol{v})$, Linear-nonlinear (LN) model: average normalized linear filters for the stimuli. $\boldsymbol{A}, \boldsymbol{B}$ (vi), Quantification of the time to peak, i.e., latency of the peaks in linear filters. $\boldsymbol{A}, \boldsymbol{B}$ (vii), Average nonlinearities of ganglion cells for the noise stimuli. $\boldsymbol{A}, \boldsymbol{B}$ (viii), Quantification of the response range of the measured response across all cells between control and Cabp $1^{-/-}$retinas.

CaBPs. Although CaBP1 can interact directly with L-type and $P / Q$ type calcium channels (Lee et al., 2002; Zhou et al., 2004; Cui et al., 2007), it could also modulate $\mathrm{Ca}^{2+}$ channel activity by protein kinase pathways. Indeed, in vitro experiments have shown that CaBP1 and CaBP2 can modulate calmodulin kinase II activity (Haeseleer et al., 2000) and calmodulin kinase II promotes the activity of T-type voltage-gated calcium channels (Welsby et al., 2003). The variety of voltage-gated calcium channels expressed in the inner retinal neurons and their specific regulation by CaBPs might thus account for the distinct effect of CaBP1/CD and CaBP2 deficiency on the transmission of light responses to ganglion cells.

CaBPs have also been shown to interact with other proteins playing an important role in neurotransmitter release. For example, CaBP5 interacts with Munc18-1, a component of the synaptic vesicle cycle. CaBP5 was suggested to have a role in synaptic vesicle priming by binding to a specific domain of Munc18-1 necessary for its interaction with the soluble $N$-ethylmaleimide-sensitive 

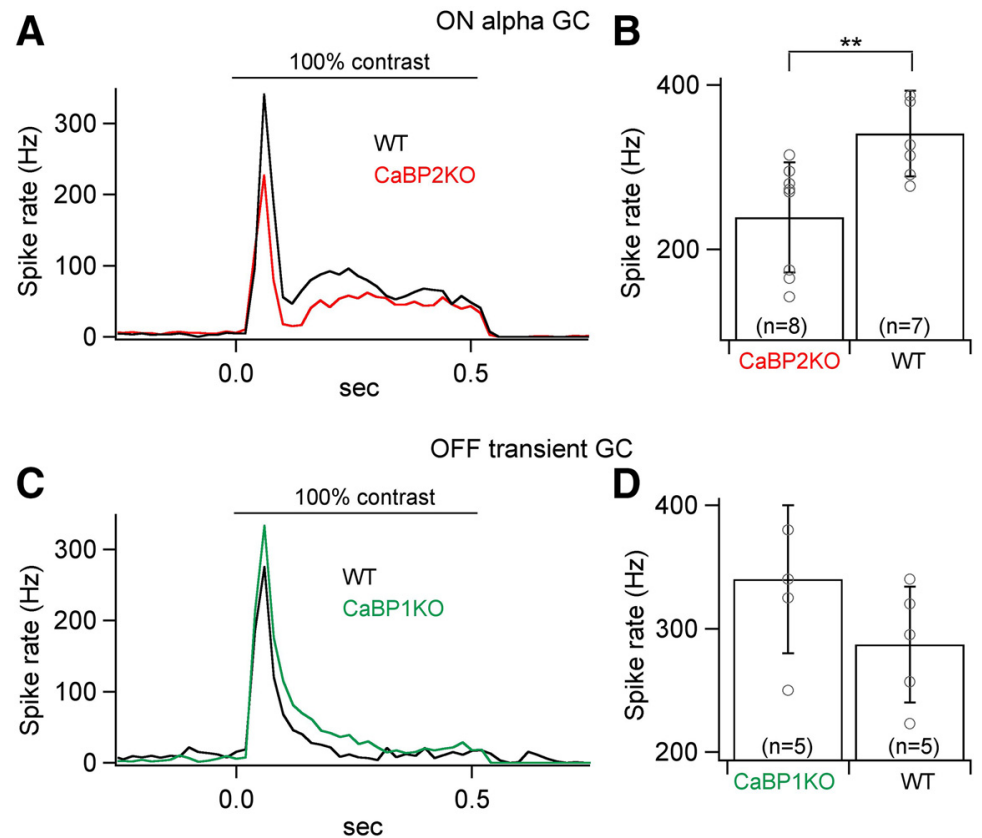

Figure 10. Spike responses of ON and OFF alpha ganglion cells in control, Cabp $1^{-/}$, and Cabp2 $2^{-/-}$mice. $\boldsymbol{A}$, Average peristimulus histogram of a spike response to a $100 \%$ contrast step in ON alpha ganglion cells in Cabp2 $2^{+/+}$and Cabp2 $2^{-/}$retinas. B, Quantification of the peak spike rate shown in $\boldsymbol{A}$. C . Average peristimulus histogram of a spike response to a $100 \%$ contrast step in OFF transient ganglion cells in Cabp $1^{+/+}$and Cabp $1^{-/-}$retinas. $\boldsymbol{D}$, Quantification of the peak spike rate shown in $\boldsymbol{C}$.

\section{ON alpha GC}

A

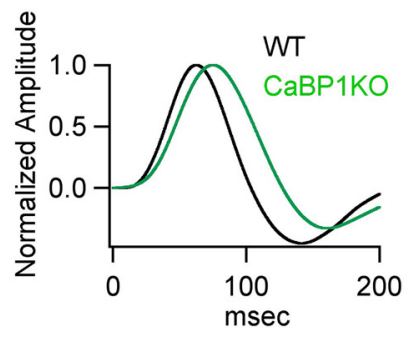

OFF transient GC

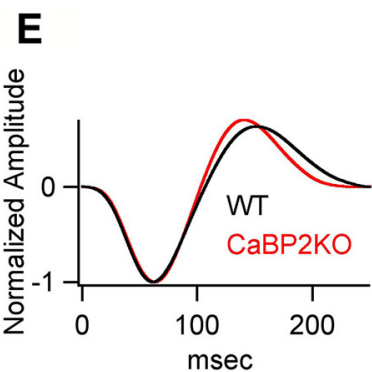

B

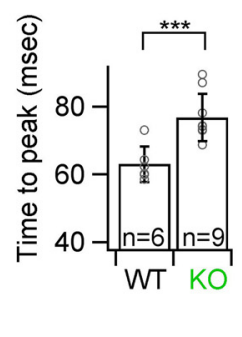

C

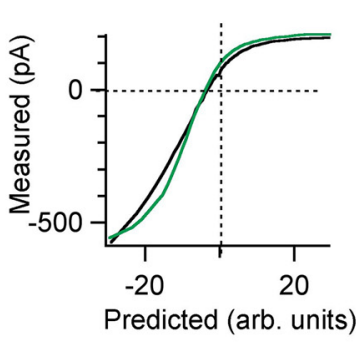

D

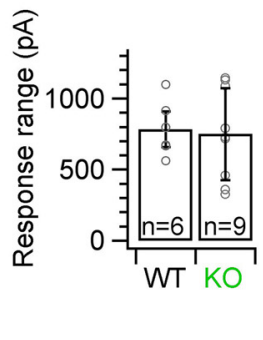

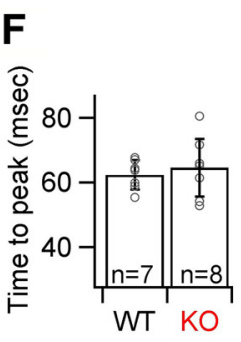

G

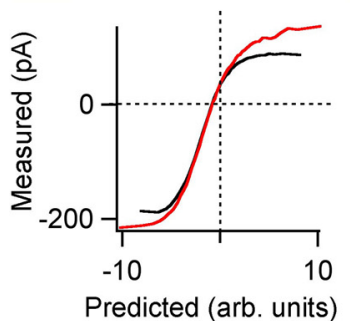

H

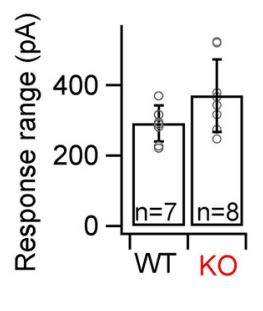

Figure 11. ON and OFF alpha ganglion cell responses in control, Cabp $1^{-1-}$, and Cabp2 $2^{-/-}$mice. Linear-nonlinear (LN) model: $\boldsymbol{A}, \boldsymbol{B}$, Average normalized linear filters and quantification of the time to peak, i.e., latency of the peaks in linear filters in Cabp $1^{-1-}$ and control retinas of $\mathrm{ON}$ alpha ganglion cells. $\boldsymbol{C}$, Average nonlinearities of $\mathrm{ON}$ alpha ganglion cells for the noise stimuli. $\boldsymbol{D}$, Quantification of the response range of the measured response across all ON alpha ganglion cells in Cabp $1^{-/-}$and control retinas. $\boldsymbol{E}, \boldsymbol{F}$, Average normalized linear filters and quantification of the time to peak, i.e., latency of the peaks in linear filters in Cabp2 ${ }^{-/-}$and control retinas of OFF transient ganglion cells. G, Average nonlinearities of OFF transient ganglion cells for the noise stimuli. $\boldsymbol{H}$, Quantification of the response range of the measured response across all OFF transient ganglion cells in $\mathrm{Cabp}^{-/-}$and control retinas. 
fusion protein attachment protein receptors (SNARE) complex. We found here that deficiency of CaBP1/CD also results in slower response kinetics than in WT animals. If $\mathrm{CaBP} 1 / \mathrm{CD}$ were to have similar effects on synaptic vesicles priming, it could affect the kinetics of the light responses.

In conclusion, the phenotype of $\mathrm{Cabp}^{-/-}$and $\mathrm{Cabp}^{-/-}$ mice gives us a first insight into the important role of CaBP1/CD and CaBP2 for normal transmission of the light responses through retinal circuits. Although the effects of CaBP1/CD and CaBP2 deficiency might result from a change of modulation of voltage-gated calcium channels, other cellular processes might also be altered. Future experiments investigating the interacting partners for CaBP1/CD and CaBP2 in bipolar cells will help to explain the visual phenotypes in the CaBP KO mice and the cellular functions of these proteins in the retina.

\section{References}

Aldahmesh MA, Al-Owain M, Alqahtani F, Hazzaa S, Alkuraya FS (2010) A null mutation in CABP4 causes Leber's congenital amaurosis-like phenotype. Mol Vis 16:207-212. Medline

Balakrishnan V, Puthussery T, Kim MH, Taylor WR, von Gersdorff H (2015) Synaptic vesicle exocytosis at the dendritic lobules of an inhibitory interneuron in the mammalian retina. Neuron 87:563575. CrossRef Medline

Bech-Hansen NT, Naylor MJ, Maybaum TA, Pearce WG, Koop B, Fishman GA, Mets M, Musarella MA, Boycott KM (1998) Loss-offunction mutations in a calcium-channel alpha(1)-subunit gene in Xp11.23 cause incomplete X-linked congenital stationary night blindness. Nat Genet 19:264-267. CrossRef

Bijveld MM, Florijn RJ, Bergen AA, van den Born LI, Kamermans M, Prick L, Riemslag FC, van Schooneveld MJ, Kappers AM, van Genderen MM (2013) Genotype and phenotype of 101 Dutch patients with congenital stationary night blindness. Ophthalmology 120:2072-2081. CrossRef Medline

Boycott KM, Maybaum TA, Naylor MJ, Weleber RG, Robitaille J, Miyake Y, Bergen AA, Pierpont ME, Pearce WG, Bech-Hansen NT (2001) A summary of 20 CACNA1F mutations identified in 36 families with incomplete $X$-linked congenital stationary night blindness, and characterization of splice variants. Hum Genet 108:9197. Medline

Chichilnisky EJ (2001) A simple white noise analysis of neuronal light responses. Netw Comput Neural Sys 12:199-213. Medline

Cui G, Meyer A, Calin-Jageman I, Neef J, Haeseleer F, Moser T, Lee A (2007) Ca2+-binding proteins tune Ca2+-feedback to Cav1.3 Ca $2+$ channels in auditory hair cells. J Physiol 585:791-803. CrossRef Medline

Dieterich DC, Karpova A, Mikhaylova M, Zdobnova I, König I, Landwehr M, Kreutz M, Smalla KH, Richter K, Landgraf P, Reissner C, Boeckers TM, Zuschratter W, Spilker C, Seidenbecher Cl, Garner CC, Gundelfinger ED, Kreutz MR (2008) Caldendrin-Jacob: a protein liaison that couples NMDA receptor signalling to the nucleus. PLoS Biol 6:e34 CrossRef Medline

Dunn FA, Wong RO (2012) Diverse strategies engaged in establishing stereotypic wiring patterns among neurons sharing a common input at the visual system's first synapse. J Neurosci 32:1030610317. CrossRef Medline

Few AP, Nanou E, Scheuer T, Catterall WA (2011) Molecular determinants of $\mathrm{Ca}(\mathrm{v}) 2.1$ channel regulation by calcium-binding protein-1. J Biol Chem 286:41917-41923. CrossRef Medline

Findeisen F, Minor DL (2010) Structural basis for the differential effects of CaBP1 and calmodulin on $\mathrm{Ca}(\mathrm{v}) 1.2$ calcium-dependent inactivation. Structure 18:1617-1631. CrossRef Medline

Ghosh KK, Bujan S, Haverkamp S, Feigenspan A, Wässle H (2004) Types of bipolar cells in the mouse retina. J Comp Neur 476:202203. CrossRef Medline
Gorny X, Mikhaylova M, Seeger C, Reddy PP, Reissner C, Schott BH, Helena Danielson U, Kreutz MR, Seidenbecher C (2012) AKAP79/ 150 interacts with the neuronal calcium-binding protein caldendrin. J Neurochem 122:714-726. CrossRef Medline

Habermann CJ, O'Brien BJ, Wässle H, Protti DA (2003) All amacrine cells express $L$-type calcium channels at their output synapses. $J$ Neurosci 23:6904-6913. Medline

Haeseleer F, Palczewski K (2002) Calmodulin and Ca2+-binding proteins (CaBPs): variations on a theme. In: Photoreceptors and calcium. Springer: New York, 303-317.

Haeseleer F, Imanishi Y, Maeda T, Possin DE, Maeda A, Lee A, Rieke F, Palczewski K (2004) Essential role of Ca2+-binding protein 4, a $\mathrm{Ca}(\mathrm{v}) 1.4$ channel regulator, in photoreceptor synaptic function. Nat Neurosci 7:1079-1087. CrossRef

Haeseleer F, Sokal I, Verlinde C, Erdjument-Bromage H, Tempst P, Pronin A, Benovic J, Fariss R, Palczewski K (2000) Five members of a novel $\mathrm{Ca} 2+-$ binding protein (CABP) subfamily with similarity to calmodulin. J Biol Chem 275:1247-1260. CrossRef

Hardie J, Lee A (2016) Decalmodulation of Cav1 channels by CaBPs. Channels (Austin) 10:33-37. CrossRef Medline

Haverkamp S, Wässle $H$ (2000) Immunocytochemical analysis of the mouse retina. J Comp Neur 424:1-23. Medline

Haverkamp S, Ghosh KK, Hirano AA, Wässle H (2003a) Immunocytochemical description of five bipolar cell types of the mouse retina. J Comp Neur 455:463-476. CrossRef Medline

Haverkamp S, Haeseleer F, Hendrickson A (2003b) A comparison of immunocytochemical markers to identify bipolar cell types in human and monkey retina. Vis Neurosci 20:589-600. Medline

Haverkamp S, Specht D, Majumdar S, Zaidi NF, Brandstätter JH, Wasco W, Wässle H, Tom Dieck S (2008) Type 4 OFF cone bipolar cells of the mouse retina express calsenilin and contact cones as well as rods. J Comp Neur 507:1087-1101. CrossRef Medline

Haynes LP, Tepikin AV, Burgoyne RD (2004) Calcium-binding protein 1 is an inhibitor of agonist-evoked, inositol 1,4,5-trisphosphatemediated calcium signaling. J Biol Chem 279:547-555. CrossRef Medline

Kaneko A, Pinto LH, Tachibana M (1989) Transient calcium current of retinal bipolar cells of the mouse. J Physiol 410:613-629. Medline

Khan AO (2013) CABP4 mutations do not cause congenital stationary night blindness. Ophthalmology 121:e15.

Khan AO, Alrashed M, Alkuraya FS (2012) Clinical characterisation of the CABP4-related retinal phenotype. Br J Ophthalmol 97:262265.

Kim KJ, Rieke F (2001) Temporal contrast adaptation in the input and output signals of salamander retinal ganglion cells. J Neurosci 21:287-299. Medline

Kim KY, Scholl ES, Liu X, Shepherd A, Haeseleer F, Lee A (2014) Localization and expression of CaBP1/caldendrin in the mouse brain. Neuroscience 268:33-47. CrossRef Medline

Lee A, Westenbroek RE, Haeseleer F, Palczewski K, Scheuer T, Catterall WA (2002) Differential modulation of $\mathrm{Ca}(\mathrm{v}) 2.1$ channels by calmodulin and Ca2+-binding protein 1. Nat Neurosci 5:210-217. CrossRef Medline

Li C, Enomoto M, Rossi AM, Seo MD, Rahman T, Stathopulos PB, Taylor CW, Ikura M, Ames JB (2013) CaBP1, a neuronal Ca2+ sensor protein, inhibits inositol trisphosphate receptors by clamping intersubunit interactions. Proc Natl Acad Sci U S A 110:85078512. CrossRef Medline

Lin B, Masland RH (2005) S(y)naptic contacts between an identified type of ON cone bipolar cell and ganglion cells in the mouse retina. Eur J Neurosci 21:1257-1270. CrossRef Medline

Mansergh F, Orton NC, Lalonde MR, Stell WK, Tremblay F, Barnes S, Rancourt DE, Bech-Hansen NT (2005) Mutation of the calcium channel gene Cacna1f disrupts calcium signaling, synaptic transmission and cellular organization in mouse retina. Hum Mol Genet 14:3035-3046. CrossRef Medline

Menger N, Seidenbecher CI, Gundelfinger ED, Kreutz MR (1999) The cytoskeleton-associated neuronal calcium-binding protein caldendrin is expressed in a subset of amacrine, bipolar and ganglion cells of the rat retina. Cell Tissue Res 298:21-32. CrossRef 
Morgan JL, Soto F, Wong RO, Kerschensteiner D (2011) Development of cell type-specific connectivity patterns of converging excitatory axons in the retina. Neuron 71:1014-1021. CrossRef Medline

Murphy GJ, Rieke F (2006) Network variability limits stimulus-evoked spike timing precision in retinal ganglion cells. Neuron 52:511-524. CrossRef Medline

Pan ZH (2000) Differential expression of high- and two types of low-voltage- activated calcium currents in rod and cone bipolar cells of the rat retina. J Neurophysiol 83:513-527. Medline

Pan ZH, Hu HJ, Perring P, Andrade R (2001) T-type Ca2+ channels mediate neurotransmitter release in retinal bipolar cells. Neuron 32:89-98. Medline

Pang JJ, Gao F, Wu SM (2003) Light-evoked excitatory and inhibitory synaptic inputs to ON and OFF alpha ganglion cells in the mouse retina. J Neurosci 23:6063-6073. Medline

Pignatelli V, Strettoi E (2004) Bipolar cells of the mouse retina: a gene gun, morphological study. J Comp Neur 476:254-266. CrossRef Medline

Rieke F (2001) Temporal contrast adaptation in salamander bipolar cells. J Neurosci 21:9445-9454. Medline

Rieke F, Lee A, Haeseleer F (2008) Characterization of Ca2+-binding protein 5 knockout mouse retina. Invest Ophthalmol Vis Sci 49: 5126-5135. CrossRef Medline

Schrauwen I, Helfmann S, Inagaki A, Predoehl F, Tabatabaiefar MA, Picher MM, Sommen M, Seco CZ, Oostrik J, Kremer H, Dheedene A, Claes C, Fransen E, Chaleshtori MH, Coucke P, Lee A, Moser T, Van Camp G (2012) A mutation in CABP2, expressed in cochlear hair cells, causes autosomal-recessive hearing impairment. Am J Hum Genet 91:636-645. CrossRef Medline

Schwartz GW, Okawa H, Dunn FA, Morgan JL, Kerschensteiner D, Wong RO, Rieke F (2012) The spatial structure of a nonlinear receptive field. Nat Neurosci 15:1572-1580. CrossRef Medline

Seidenbecher $\mathrm{Cl}$, Langnaese K, Sanmartí-Vila L, Boeckers TM, Smalla KH, Sabel BA, Garner CC, Gundelfinger ED, Kreutz MR (1998) Caldendrin, a novel neuronal calcium-binding protein confined to the somato-dendritic compartment. J Biol Chem 273: 21324-21331. Medline

Seidenbecher CI, Landwehr M, Smalla KH, Kreutz M, Dieterich DC, Zuschratter W, Reissner C, Hammarback JA, Böckers TM, Gundelfinger ED, Kreutz MR (2004) Caldendrin but not calmodulin binds to light chain 3 of MAP1A/B: an association with the microtubule cytoskeleton highlighting exclusive binding partners for neuronal $\mathrm{Ca}(2+)$-sensor proteins. J Mol Biol 336:957-970. CrossRef

Shaltiel L, Paparizos C, Fenske S, Hassan S, Gruner C, Rotzer K, Biel M,CAW-S (2012) Complex regulation of voltage-dependent activation and inactivation properties of retinal voltage-gated Cav1.4 L-type $\mathrm{Ca} 2+$ channels by $\mathrm{Ca} 2+$-binding protein 4 (CaBP4). J Biol Chem 287:36312-36321.
Singer JH, Diamond JS (2003) Sustained Ca2 + entry elicits transient postsynaptic currents at a retinal ribbon synapse. J Neurosci 23:10923-10933. Medline

Sokal I, Haeseleer $\mathrm{F}$ (2011) Insight into the role of $\mathrm{Ca}(2+)$-binding protein 5 in vesicle exocytosis. Invest Ophthalmol Vis Sci 52:91319141. CrossRef Medline

Sokal I, Li N, Verlinde C, Haeseleer F, Baehr W, Palczewski K (2000) $\mathrm{Ca} 2+-$ binding proteins in the retina: from discovery to etiology of human disease. Biochim Biophys Acta Mol Cell Res 1498:233251. Medline

Strom TM, Nyakatura G, Apfelstedt-Sylla E, Hellebrand H, Lorenz B, Weber BHF, Wutz K, Gutwillinger N, Rüther K, Drescher B, Sauer C, Zrenner E, Meitinger T, Rosenthal A, Meindl A (1998) An L-type calcium-channel gene mutated in incomplete $X$-linked congenital stationary night blindness. Nat Genet 19:260-263. CrossRef

van Wyk M, Wässle H, Taylor WR (2009) Receptive field properties of ON- and OFF-ganglion cells in the mouse retina. Vis Neurosci 26:297-308. CrossRef Medline

Wässle H (2004) Parallel processing in the mammalian retina. Nat Rev Neurosci 5:747-757. CrossRef

Wässle H, Puller C, Müller F, Haverkamp S (2009) Cone contacts, mosaics, and territories of bipolar cells in the mouse retina. $J$ Neurosci 29:106-117. CrossRef Medline

Welsby PJ, Wang H, Wolfe JT, Colbran RJ, Johnson ML, Barrett PQ (2003) A mechanism for the direct regulation of T-type calcium channels by $\mathrm{Ca} 2+/$ calmodulin-dependent kinase II. J Neurosci 23:10116-10121.

Wutz K, Sauer C, Zrenner E, Lorenz B, Alitalo T, Broghammer M, Hergersberg $M$, de La Chapelle A, Weber BHF, Wissinger B, Meindl A, Pusch CM (2002) Thirty distinct CACNA1F mutations in 33 families with incomplete type of XLCSNB and Cacna1f expression profiling in mouse retina. Eur $\mathrm{J}$ Hum Genet 10:449-456. CrossRef

Yang J, McBride S, Mak DOD, Vardi N, Palczewski K, Haeseleer F, Foskett JK (2002) Identification of a family of calcium sensors as protein ligands of inositol trisphosphate receptor $\mathrm{Ca} 2+$ release channels. Proc Natl Acad Sci U S A 99:7711-7716. CrossRef

Yang PS, Alseikhan BA, Hiel H, Grant L, Mori MX, Yang WJ, Fuchs PA, Yue DT (2006) Switching of Ca2+-dependent inactivation of $\mathrm{Ca}(\mathrm{V}) 1.3$ channels by calcium binding proteins of auditory hair cells. J Neurosci 26:10677-10689. CrossRef

Zeitz C, Kloeckener-Gruissem B, Forster U, Kohl S, Magyar I, Wissinger B, Mátyás G, Borruat FX, Schorderet DF, Zrenner E, Munier FL, Berger W (2006) Mutations in CABP4, the gene encoding the $\mathrm{Ca} 2+-$ binding protein 4 , cause autosomal recessive night blindness. Am J Hum Genet 79:657-667. CrossRef Medline

Zhou H, Kim SA, Kirk EA, Tippens AL, Sun H, Haeseleer F, Lee A (2004) Ca2+-binding protein-1 facilitates and forms a postsynaptic complex with $\mathrm{Ca}(\mathrm{v}) 1.2$ (L-Type) $\mathrm{Ca} 2+$ channels. J Neurosci 24:4698-4708. CrossRef Medline 